\title{
On a Class of Efficient Higher Order Newton-like Methods
}

\author{
Janak Raj Sharma and Deepak Kumar \\ Department of Mathematics, Sant Longowal Institute of Engineering and \\ Technology \\ Longowal, 148106 Sangrur, India \\ E-mail(corresp.): jrshira@yahoo.co.in \\ E-mail: deepak.babbi@gmail.com
}

Received April 30, 2018; revised November 19, 2018; accepted November 20, 2018

\begin{abstract}
Based on a two-step Newton-like scheme, we propose a three-step scheme of convergence order $p+2(p \geq 3)$ for solving systems of nonlinear equations. Furthermore, on the basis of this scheme a generalized $k+2$-step scheme with increasing convergence order $p+2 k$ is presented. Local convergence analysis, including radius of convergence and uniqueness results of the methods, is presented. Computational efficiency in the general form is discussed. Theoretical results are verified through numerical experimentation. Finally, performance is demonstrated by application of the methods on some nonlinear systems of equations.
\end{abstract}

Keywords: Newton-like methods, convergence, Fréchet-derivative, computational efficiency.

AMS Subject Classification: 49M15; 41A25; 65H10; 65J10.

\section{Introduction}

The construction of fixed point iterative methods for solving nonlinear equations or systems of nonlinear equations is an interesting and challenging task in numerical analysis and many applied scientific branches. The huge importance of this subject has led to the development of many numerical methods, most frequently of iterative nature (see $[1,12]$ ). With the advancement of computer hardware and software, the problem of solving nonlinear equations by numerical methods has gained an additional importance. In this paper, we consider the problem of approximating a solution $x^{*}$ of the equation $F(x)=0$, where $F: \Omega \subseteq B_{1} \rightarrow B_{2}, B_{1}$ and $B_{2}$ are Banach spaces and $\Omega$ is a nonempty open 
convex subset of $B_{1}$, by iterative methods of a high order of convergence. The solution $x^{*}$ can be obtained as a fixed point of some function $\Phi: \Omega \subseteq B_{1} \rightarrow B_{2}$ by means of fixed point iteration

$$
x_{n+1}=\Phi\left(x_{n}\right), \quad n=0,1,2, \ldots .
$$

There are a variety of iterative methods for solving nonlinear equations. A basic method is the well-known quadratically convergent Newton's method [1]

$$
x_{n+1}=x_{n}-F^{\prime}\left(x_{n}\right)^{-1} F\left(x_{n}\right),
$$

where $F^{\prime}(x)^{-1}$ is the inverse of first Fréchet derivative $F^{\prime}(x)$ of the function $F(x)$. This method converges if the initial approximation $x_{0}$ is closer to solution $x^{*}$ and $F^{\prime}(x)^{-1}$ exists in the neighborhood $\Omega$ of $x^{*}$. In order to attain the higher order of convergence, a number of modified Newton's or Newton-like methods have been proposed in literature, see, for example $[3,4,5,6,7,8,9,10,11,14]$ and references therein.

The main goal and motivation in developing iterative methods is to achieve as high as possible convergence order by consuming as small as possible function evaluations and inverse operators. With these considerations, here we propose multipoint iterative methods with increasing order of convergence. First, we present a three-step scheme of convergence order $p+2$ whose first two steps belong to a class of Newton-like iterations of convergence order $p(\geq 3)$ whereas the third step is also a modification of Newton's scheme. Furthermore, based on this three-step scheme a generalized $k+2$-step scheme with increasing convergence order $p+2 k(k \in \mathbb{N})$ is presented.

Rest of the paper is structured as follows. In Section 2, the three-step method is developed and its $p+2$-th order convergence is established. Then, the generalized version consisting of $k+2$-step scheme with convergence order $p+2 k$ is presented in Section 3. In Section 4, the detailed convergence analysis is carried out. Analysis of computational efficiency of the methods is performed in Section 5. In order to verify the theoretical results, some numerical examples are presented in Section 6. Finally, the methods are applied to solve systems of nonlinear equations in Section 7.

\section{Development of method}

Let us begin with the following three-step scheme

$$
\begin{aligned}
& y_{n}=x_{n}-F^{\prime}\left(x_{n}\right)^{-1} F\left(x_{n}\right), \quad z_{n}=\varphi^{(p)}\left(x_{n}, y_{n}\right), \\
& x_{n+1}=z_{n}-\left(a I+b F^{\prime}\left(x_{n}\right)^{-1}\left[z_{n}, y_{n} ; F\right]\right) F^{\prime}\left(x_{n}\right)^{-1} F\left(z_{n}\right),
\end{aligned}
$$

where $\varphi^{(p)}\left(x_{n}, y_{n}\right)$ is any iterative scheme of convergence order $p \geq 3, I$ is an identity operator, $\left[z_{n}, y_{n} ; F\right]$ is the first order divided difference and $a, b$ are free parameters to be determined in the sequel.

To obtain the convergence order of (2.1), we require the definition of divided difference. For this, recalling the following result of Taylor's expansion on vector functions (see [12]): 
Lemma 1. Let $F: \Omega \subset \mathbb{R}^{m} \rightarrow \mathbb{R}^{m}$ be $r$-times Fréchet differentiable in a convex set $\Omega \subset \mathbb{R}^{m}$. Then, for any $x, h \in \mathbb{R}^{m}$, the following expression holds:

$$
\begin{aligned}
F(x+h)=F(x) & +F^{\prime}(x) h+\frac{1}{2 !} F^{\prime \prime}(x) h^{2}+\frac{1}{3 !} F^{\prime \prime \prime}(x) h^{3}+\ldots \\
& +\frac{1}{(r-1) !} F^{(r-1)}(x) h^{r-1}+R_{r},
\end{aligned}
$$

where $\left\|R_{r}\right\| \leqslant \frac{1}{r !} \sup _{0 \leqslant t \leqslant 1}\left\|F^{(r)}(x+t h)\right\|\|h\|^{r}$ and $h^{r}=(h, h, . r ., h)$.

The divided difference operator of $F$ is a mapping $[\cdot, \cdot ; F]: \Omega \times \Omega \subset \mathbb{R}^{m} \times$ $\mathbb{R}^{m} \longrightarrow L\left(\mathbb{R}^{m}\right)$ defined by (see $\left.[12]\right)$

$$
[x+h, x ; F]=\int_{0}^{1} F^{\prime}(x+t h) d t, \forall x, h \in \mathbb{R}^{m} .
$$

Expanding $F^{\prime}(x+t h)$ in Taylor series at the point $x$ and integrating, we have

$$
[x+h, x ; F]=\int_{0}^{1} F^{\prime}(x+t h) d t=F^{\prime}(x)+\frac{1}{2} F^{\prime \prime}(x) h+\frac{1}{6} F^{\prime \prime \prime}(x) h^{2}+O\left(h^{3}\right),
$$

where $h^{i}=(h, h, . \stackrel{i}{.}, h), h \in \mathbb{R}^{m}$. Let $e_{n}=x_{n}-x^{*}$. Developing $F\left(x_{n}\right)$ in a neighborhood of $x^{*}$ and assuming that $\Gamma=F^{\prime}\left(x^{*}\right)^{-1}$ exists, we have

$$
F\left(x_{n}\right)=F^{\prime}\left(x^{*}\right)\left(e_{n}+A_{2}\left(e_{n}\right)^{2}+A_{3}\left(e_{n}\right)^{3}+A_{4}\left(e_{n}\right)^{4}+O\left(\left(e_{n}\right)^{5}\right)\right),
$$

where $A_{i}=\frac{1}{i !} \Gamma F^{(i)}\left(x^{*}\right) \in L_{i}\left(\mathbb{R}^{m}, \mathbb{R}^{m}\right)$ and $\left(e_{n}\right)^{i}=\left(e_{n}, e_{n}, . i ., e_{n}\right), e_{n} \in \mathbb{R}^{m}$, $i=2,3, \ldots$. Also,

$$
\begin{aligned}
& F^{\prime}\left(x_{n}\right)=F^{\prime}\left(x^{*}\right)\left(I+2 A_{2} e_{n}+3 A_{3}\left(e_{n}\right)^{2}+4 A_{4}\left(e_{n}\right)^{3}+O\left(\left(e_{n}\right)^{4}\right)\right), \\
& F^{\prime \prime}\left(x_{n}\right)=F^{\prime}\left(x^{*}\right)\left(2 A_{2}+6 A_{3} e_{n}+12 A_{4}\left(e_{n}\right)^{2}+O\left(\left(e_{n}\right)^{3}\right)\right), \\
& F^{\prime \prime \prime}\left(x_{n}\right)=F^{\prime}\left(x^{*}\right)\left(6 A_{3}+24 A_{4} e_{n}+O\left(\left(e_{n}\right)^{2}\right)\right) .
\end{aligned}
$$

Inversion of $F^{\prime}\left(x_{n}\right)$ yields,

$$
\begin{gathered}
F^{\prime}\left(x_{n}\right)^{-1}=\left(I-2 A_{2} e_{n}+\left(4 A_{2}^{2}-3 A_{3}\right)\left(e_{n}\right)^{2}-\left(4 A_{4}-6 A_{2} A_{3}-6 A_{3} A_{2}\right.\right. \\
\left.\left.+8 A_{2}^{3}\right)\left(e_{n}\right)^{3}+O\left(\left(e_{n}\right)^{4}\right)\right) \Gamma .
\end{gathered}
$$

Now we can analyze the convergence behavior of scheme (2.1). Thus, the following theorem is proved:

Theorem 1. Suppose that (i) $F: \Omega \subset \mathbb{R}^{m} \rightarrow \mathbb{R}^{m}$ is a sufficiently many times differentiable mapping, (ii) There exists a solution $x^{*} \in \Omega$ of equation $F(x)=0$ such that $F^{\prime}\left(x^{*}\right)$ is nonsingular. Then, sequence $\left\{x_{n}\right\}$ generated by method (2.1) for $x_{0} \in \Omega$ converges to $x^{*}$ with order $p+2$ for $p \geq 3$, provided that $a=2$ and $b=-1$.

Proof. From (2.3) and (2.5), it follows that

$$
F^{\prime}\left(x_{n}\right)^{-1} F\left(x_{n}\right)=e_{n}-A_{2}\left(e_{n}\right)^{2}+2\left(A_{2}^{2}-A_{3}\right)\left(e_{n}\right)^{3}+O\left(\left(e_{n}\right)^{4}\right) .
$$


For $\tilde{e}_{n}=y_{n}-x^{*}$, we have that

$$
\tilde{e}_{n}=A_{2}\left(e_{n}\right)^{2}-2\left(A_{2}^{2}-A_{3}\right)\left(e_{n}\right)^{3}+O\left(\left(e_{n}\right)^{4}\right) .
$$

By hypothesis, $\left\{z_{n}\right\}$ is of order $p$. Set $\bar{e}_{n}=z_{n}-x^{*}=K\left(\left(e_{n}\right)^{p}\right)+O\left(\left(e_{n}\right)^{p+1}\right)$, $K \neq 0$. Using Equations (2.4) in (2.2) for $x+h=z_{n}, x=y_{n}$ and $h=\bar{e}_{n}-\tilde{e}_{n}$, it follows that

$$
\begin{aligned}
& {\left[z_{n}, y_{n} ; F\right]=F^{\prime}\left(x^{*}\right)\left(I+A_{2}\left(\bar{e}_{n}+\tilde{e}_{n}\right)+O\left(\left(\tilde{e}_{n}\right)^{2},\left(\bar{e}_{n}\right)^{2}\right)\right),} \\
& F^{\prime}\left(x_{n}\right)^{-1}\left[z_{n}, y_{n} ; F\right]=I-2 A_{2} e_{n}+\left(4 A_{2}^{2}-3 A_{3}\right)\left(e_{n}\right)^{2}+A_{2}\left(\bar{e}_{n}+\tilde{e}_{n}\right)+O\left(\left(e_{n}\right)^{3}\right) .
\end{aligned}
$$

Consequently, summing up we get in turn that

$$
\begin{aligned}
a I+b F^{\prime}\left(x_{n}\right)^{-1}\left[z_{n}, y_{n} ; F\right]= & (a+b) I-2 b A_{2} e_{n}+b\left(4 A_{2}^{2}-3 A_{3}\right)\left(e_{n}\right)^{2} \\
& +b A_{2}\left(\bar{e}_{n}+\tilde{e}_{n}\right)+O\left(\left(e_{n}\right)^{3}\right) .
\end{aligned}
$$

Then

$$
\begin{aligned}
& \left(a I+b F^{\prime}\left(x_{n}\right)^{-1}\left[z_{n}, y_{n} ; F\right]\right) F^{\prime}\left(x_{n}\right)^{-1}=\left((a+b) I-2 A_{2}(a+2 b) e_{n}\right. \\
& \left.\quad+\left(4(a+3 b) A_{2}^{2}-3(a+2 b) A_{3}\right)\left(e_{n}\right)^{2}+b A_{2}\left(\bar{e}_{n}+\tilde{e}_{n}\right)+O\left(\left(e_{n}\right)^{3}\right)\right) \Gamma .
\end{aligned}
$$

Also, we have

$$
F\left(z_{n}\right)=F^{\prime}\left(x^{*}\right)\left(\bar{e}_{n}+O\left(\left(\bar{e}_{n}\right)^{2}\right)\right) .
$$

Using (2.6) and (2.7) in the third substep of method (2.1), it follows that

$$
\begin{aligned}
e_{n+1}= & (1-a-b) \bar{e}_{n}+2 A_{2}(a+2 b) e_{n} \bar{e}_{n}-\left(4(a+3 b) A_{2}^{2}\right. \\
& \left.-3(a+2 b) A_{3}\right)\left(e_{n}\right)^{2} \bar{e}_{n}-b A_{2} \tilde{e}_{n} \bar{e}_{n}+O\left(\left(e_{n}\right)^{3} \bar{e}_{n}\right) .
\end{aligned}
$$

Our aim is to find the values of parameters $a$ and $b$ in such a way that the proposed iterative scheme may produce order of convergence as high as possible. Thus, it will suffice to equate coefficients of first two terms to zero, which implies that $1-a-b=0$ and $a+2 b=0$. Solving, we get $a=2$ and $b=-1$. Therefore, the error equation (2.8) reduces to

$$
e_{n+1}=5 K A_{2}^{2}\left(e_{n}\right)^{p+2}+O\left(\left(e_{n}\right)^{p+3}\right) .
$$

This shows that the convergence to $x^{*}$ is of order $p+2(p \geq 3)$.

\section{$3 \quad$ Generalized method}

The generalization of method (2.1), consisting of $k+2$ steps, is expressed as

$$
\begin{aligned}
& y_{n}=x_{n}-F^{\prime}\left(x_{n}\right)^{-1} F\left(x_{n}\right), \quad z_{n}=\varphi^{(p)}\left(x_{n}, y_{n}\right), \\
& z_{n}^{(1)}=z_{n}-\psi\left(x_{n}, y_{n}\right) F\left(z_{n}\right), \quad z_{n}^{(2)}=z_{n}^{(1)}-\psi\left(x_{n}, y_{n}\right) F\left(z_{n}^{(1)}\right), \\
& \ldots \ldots \ldots \ldots \ldots \ldots \\
& z_{n}^{(k-1)}=z_{n}^{(k-2)}-\psi\left(x_{n}, y_{n}\right) F\left(z_{n}^{(k-2)}\right), \\
& z_{n}^{(k)}=x_{n+1}=z_{n}^{(k-1)}-\psi\left(x_{n}, y_{n}\right) F\left(z_{n}^{(k-1)}\right),
\end{aligned}
$$

where $k \in \mathbb{N}, z_{n}^{(0)}=z_{n}$ and $\psi\left(x_{n}, y_{n}\right)=\left(2 I-F^{\prime}\left(x_{n}\right)^{-1}\left[z_{n}, y_{n} ; F\right]\right) F^{\prime}\left(x_{n}\right)^{-1}$. 
Theorem 2. Under the hypotheses of Theorem 1, the sequence $\left\{x_{n}\right\}$ generated by method (3.1) for $x_{0} \in \Omega$ converges to $x^{*}$ with order $p+2 k$ for $p \geq 3$ and $k \in \mathbb{N}$.

Proof. From (2.6), we have that

$$
\psi\left(x_{n}, y_{n}\right)=\left(I-5 A_{2}^{2}\left(e_{n}\right)^{2}+\ldots\right) \Gamma .
$$

Taylor's expansion of $F\left(z_{n}^{(k-1)}\right)$ about $x^{*}$ yields

$$
F\left(z_{n}^{(k-1)}\right)=F^{\prime}\left(x^{*}\right)\left(\left(z_{n}^{(k-1)}-x^{*}\right)+A_{2}\left(z_{n}^{(k-1)}-x^{*}\right)^{2}+\ldots\right) .
$$

Then, we have that

$$
\begin{aligned}
\psi\left(x_{n}, y_{n}\right) F\left(z_{n}^{(k-1)}\right)= & \left(z_{n}^{(k-1)}-x^{*}\right)-5 A_{2}^{2}\left(e_{n}\right)^{2}\left(z_{n}^{(k-1)}-x^{*}\right) \\
& +A_{2}\left(z_{n}^{(k-1)}-x^{*}\right)^{2}+\ldots
\end{aligned}
$$

Using (3.2) in the last step of (3.1), we obtain

$$
z_{n}^{(k)}-x^{*}=5 A_{2}^{2}\left(e_{n}\right)^{2}\left(z_{n}^{(k-1)}-x^{*}\right)-A_{2}\left(z_{n}^{(k-1)}-x^{*}\right)^{2}+\ldots
$$

As we know that $z_{n}^{(1)}-x^{*}=5 K A_{2}^{2}\left(e_{n}\right)^{p+2}+O\left(\left(e_{n}\right)^{p+3}\right)$, therefore, from $(3.3)$ for $k=2,3$, we have

$$
\begin{aligned}
& z_{n}^{(2)}-x^{*}=5 A_{2}^{2}\left(e_{n}\right)^{2}\left(z_{n}^{(1)}-x^{*}\right)+\ldots=5^{2} K A_{2}^{4}\left(e_{n}\right)^{p+4}+O\left(\left(e_{n}\right)^{p+5}\right), \\
& z_{n}^{(3)}-x^{*}=5 A_{2}^{2}\left(e_{n}\right)^{2}\left(z_{n}^{(2)}-x^{*}\right)+\ldots=5^{3} K A_{2}^{6}\left(e_{n}\right)^{p+6}+O\left(\left(e_{n}\right)^{p+7}\right) .
\end{aligned}
$$

Proceeding by induction, we have

$$
e_{n+1}=z_{n}^{(k)}-x^{*}=5^{q} K A_{2}^{2 k}\left(e_{n}\right)^{p+2 k}+O\left(\left(e_{n}\right)^{p+2 k+1}\right) .
$$

This completes the proof of Theorem 2 .

\section{Local convergence}

In this section, we study the convergence of new methods in Banach space setting. Let $w_{0}: \mathbb{R}_{+} \cup\{0\} \rightarrow \mathbb{R}_{+} \cup\{0\}$ be a continuous and nondecreasing function with $w_{0}(0)=0$. Let also $r$ be the smallest positive solution of equation

$$
w_{0}(t)=1
$$

Consider the function $w:[0, r) \rightarrow \mathbb{R}_{+} \cup\{0\}$ continuous and nondecreasing with $w(0)=0$. Define functions $g_{1}$ and $h_{1}$ on the interval $[0, r)$ by

$$
g_{1}(t)=\frac{\int_{0}^{1} w((1-\theta) t) d \theta}{1-w_{0}(t)}, \quad h_{1}(t)=g_{1}(t)-1 .
$$

We have $h_{1}(0)=-1<0$ and $h_{1}(t) \rightarrow+\infty$ as $t \rightarrow r^{-}$. The intermediate value theorem guarantees that equation $h_{1}(t)=0$ has solutions in $(0, r)$. Denote by 
$r_{1}$ the smallest such solution. Let $\lambda>1$ and $g_{2}:\left[0, r_{1}\right) \rightarrow \mathbb{R}_{+} \cup\{0\}$ be a continuous and nondecreasing function. Define function $h_{2}$ on $\left[0, r_{1}\right)$ by

$$
h_{2}(t)=g_{2}(t) t^{\lambda-1}-1 \text {. }
$$

Suppose that $g_{2}(t) t^{\lambda-1}-1 \rightarrow+\infty$ or a positive number as $t \rightarrow r_{1}^{-}$. Then, we get that $h_{2}(0)=-1<0$ and $h_{2}(t) \rightarrow+\infty$ or a positive number as $t \rightarrow r_{1}^{-}$. Denote by $r_{2}$ the smallest solution in $\left(0, r_{1}\right)$ of equation $h_{2}(t)=0$. If $\lambda=1$, suppose instead of (4.1) that

$$
g_{2}(0)<1
$$

and $g_{2}(t)-1 \rightarrow+\infty$ or a positive number as $t \rightarrow r_{1}^{-}$. Denote again by $r_{2}$ the smallest solution of equation $h_{2}(t)=0$.

Let $v_{0}:[0, r) \rightarrow \mathbb{R}_{+} \cup\{0\}$ be a continuous and nondecreasing function. Define functions $p, g_{3}$ and $h_{3}$ on the interval $\left(0, r_{1}\right)$ by

$$
\begin{aligned}
& p(t)=1+\frac{w_{0}(t)+v_{0}\left(\left(g_{2}(t)+g_{1}(t)\right) t\right)}{1-w_{0}(t)}, \\
& g_{3}(t)=\left(1+\frac{M p(t)}{1-w_{0}(t)}\right) g_{2}(t) t^{\lambda-1}, \quad h_{3}(t)=g_{3}(t)-1 .
\end{aligned}
$$

We obtain that $h_{3}(0)=-1<0$ and $h_{3}(t) \rightarrow \infty$ as $t \rightarrow r_{1}^{-}$. Denote by $r_{3}$ the smallest solution of equation $h_{3}(t)=0$ in $\left(0, r_{2}\right)$. Then, we have that for each $t \in[0, r)$

$$
0 \leq g_{i}(t)<1, \quad i=1,2,3 .
$$

Denote by $U(\mu, \varepsilon)=\left\{x \in B_{1}:\|x-\mu\|<\varepsilon\right\}$ the ball with center $\mu \in B_{1}$ and of radius $\varepsilon>0$. Furthermore, let $\bar{U}(\mu, \varepsilon)$ be the closure of $U(\mu, \varepsilon)$. We shall show the local convergence analysis of method (2.1) in a Banach space setting under hypotheses (A):

(a1) $F: \Omega \subseteq B_{1} \rightarrow B_{2}$ is a continuously Fréchet-differentiable operator and $[., . ; F]: \Omega \times \Omega \rightarrow \mathcal{L}\left(B_{1}, B_{2}\right)$ be a divided difference operator of $F$.

(a2) There exists $x^{*} \in \Omega$ such that $F\left(x^{*}\right)=0$ and $F^{\prime}\left(x^{*}\right)^{-1} \in \mathcal{L}\left(B_{2}, B_{1}\right)$.

(a3) There exists function $w_{0}: \mathbb{R}_{+} \cup\{0\} \rightarrow \mathbb{R}_{+} \cup\{0\}$ continuous and nondecreasing with $w_{0}(0)=0$ such that for each $x \in \Omega$

$$
\left\|F^{\prime}\left(x^{*}\right)^{-1}\left(F^{\prime}(x)-F^{\prime}\left(x^{*}\right)\right)\right\| \leq w_{0}\left(\left\|x-x^{*}\right\|\right) .
$$

(a4) Let $\Omega_{0}=\Omega \cap U\left(x^{*}, r\right)$, where $r$ was defined previously. There exist functions $w:[0, r) \rightarrow \mathbb{R}_{+} \cup\{0\}, v_{0}:[0, r) \rightarrow \mathbb{R}_{+} \cup\{0\}$ continuous and nondecreasing with $w(0)=0$ such that for each $x, y \in \Omega_{0}$

$$
\begin{aligned}
& \left\|F^{\prime}\left(x^{*}\right)^{-1}\left(F^{\prime}(x)-F^{\prime}(y)\right)\right\| \leq w(\|x-y\|), \\
& \left\|F^{\prime}\left(x^{*}\right)^{-1}\left(F^{\prime}\left(x^{*}\right)-[z, y ; F]\right)\right\| \leq v_{0}\left(\left\|z-x^{*}\right\|+\left\|y-x^{*}\right\|\right) .
\end{aligned}
$$

(a5) There exists function $g_{2}:\left[0, r_{1}\right) \rightarrow \mathbb{R}_{+} \cup\{0\}$ continuous and nondecreasing and $\lambda \geq 1$ satisfying (4.1) if $\lambda>1$ and (4.2) if $\lambda=1$ such that

$$
\left\|\varphi\left(x, x-F^{\prime}(x)^{-1} F^{\prime}(x)\right)-x^{*}\right\| \leq g_{2}\left(\left\|x-x^{*}\right\|\right)\left\|x-x^{*}\right\|^{\lambda} .
$$

(a6) $\bar{U}\left(x^{*}, r_{3}\right) \subseteq \Omega$ and $\left\|F^{\prime}\left(x^{*}\right)^{-1} F^{\prime}(x)\right\| \leq M$.

(a7) Let $r^{*} \geq r_{3}$ and set $\Omega_{1}=\Omega \cap \bar{U}\left(x^{*}, r^{*}\right), \int_{0}^{1} w_{0}\left(\theta r^{*}\right) d \theta<1$. 
Theorem 3. Suppose that the hypotheses (A) are satisfied. Then, the sequence $\left\{x_{n}\right\}$ generated for $x_{0} \in U\left(x^{*}, r_{3}\right)-\left\{x^{*}\right\}$ by method (2.1) is well defined in $U\left(x^{*}, r_{3}\right)$, remains in $U\left(x^{*}, r_{3}\right)$ for all $n=0,1,2, \ldots$ and converges to $x^{*}$, so that

$$
\begin{aligned}
\left\|y_{n}-x^{*}\right\| & \leq g_{1}\left(\left\|x_{n}-x^{*}\right\|\right)\left\|x_{n}-x^{*}\right\| \leq\left\|x_{n}-x^{*}\right\|<r_{3}, \\
\left\|z_{n}-x^{*}\right\| & \leq g_{2}\left(\left\|x_{n}-x^{*}\right\|\right)\left\|x_{n}-x^{*}\right\|^{\lambda} \leq\left\|x_{n}-x^{*}\right\|, \\
\left\|x_{n+1}-x^{*}\right\| & \leq g_{3}\left(\left\|x_{n}-x^{*}\right\|\right)\left\|x_{n}-x^{*}\right\| \leq\left\|x_{n}-x^{*}\right\|,
\end{aligned}
$$

where the functions $g_{i}, i=1,2,3$, are defined previously. Moreover, the vector $x^{*}$ is the only solution of equation $F(x)=0$ in $\Omega_{1}$.

Proof. We shall show estimates (4.4)-(4.6) using mathematical induction. By hypothesis (a3) and for $x \in U\left(x^{*}, r_{3}\right)$, we have that

$$
\left\|F^{\prime}\left(x^{*}\right)^{-1}\left(F^{\prime}(x)-F^{\prime}\left(x^{*}\right)\right)\right\| \leq w_{0}\left(\left\|x-x^{*}\right\|\right) \leq w_{0}\left(r_{3}\right)<1 .
$$

By the Banach perturbation Lemma [2] and (4.7) we get that $F^{\prime}(x)^{-1} \in$ $\mathcal{L}\left(B_{2}, B_{1}\right)$ and

$$
\left\|F^{\prime}(x)^{-1} F^{\prime}\left(x^{*}\right)\right\| \leq 1 /\left(1-w_{0}\left(\left\|x-x^{*}\right\|\right)\right) .
$$

In particular, (4.8) holds for $x=x_{0}$, since $x_{0} \in U\left(x^{*}, r_{3}\right)-\left\{x^{*}\right\}$ and $y_{0}, z_{0}$ are well defined by the first and second substep of method (2.1) for $n=0$. We can write by the first substep of method (2.1) and (a2) that

$$
\begin{aligned}
y_{0}-x^{*} & =x_{0}-x^{*}-F^{\prime}\left(x_{0}\right)^{-1} F\left(x_{0}\right) \\
& =\int_{0}^{1} F^{\prime}\left(x_{0}\right)^{-1}\left(F^{\prime}\left(x^{*}+\theta\left(x_{0}-x^{*}\right)\right)-F^{\prime}\left(x_{0}\right)\right)\left(x_{0}-x^{*}\right) d \theta .
\end{aligned}
$$

Then, using (4.3) (for $i=1$ ), the first condition in (a4), (4.8) (for $x=x_{0}$ ) and (4.9) we get in turn that

$$
\begin{aligned}
\| y_{0}- & x^{*}\|=\| F^{\prime}\left(x_{0}\right)^{-1} F^{\prime}\left(x^{*}\right)\|\| \int_{0}^{1} F^{\prime}\left(x^{*}\right)^{-1}\left[F^{\prime}\left(x^{*}+\theta\left(x_{0}-x^{*}\right)-F^{\prime}\left(x_{0}\right)\right] d \theta \|\right. \\
& \times\left\|x_{0}-x^{*}\right\| \leq \frac{\int_{0}^{1} w\left((1-\theta)\left\|x_{0}-x^{*}\right\|\right) d \theta\left\|x_{0}-x^{*}\right\|}{1-w_{0}\left(\left\|x_{0}-x^{*}\right\|\right)} \\
& =g_{1}\left(\left\|x_{0}-x^{*}\right\|\right)\left\|x_{0}-x^{*}\right\| \leq\left\|x_{0}-x^{*}\right\|<r_{3}
\end{aligned}
$$

which implies (4.4) for $n=0$ and $y_{0} \in U\left(x^{*}, r_{3}\right)$. Using (a5) and (4.3) (for $i=2$ ), we get that

$$
\left\|z_{0}-x^{*}\right\|=\left\|\varphi\left(x_{0}, y_{0}\right)-x^{*}\right\| \leq g_{2}\left(\left\|x_{0}-x^{*}\right\|\right)\left\|x_{0}-x^{*}\right\|^{\lambda} \leq\left\|x_{0}-x^{*}\right\|<r_{3},
$$

so (4.5) holds for $n=0$ and $z_{0} \in U\left(x^{*}, r_{3}\right)$. Notice that since $y_{0}, z_{0} \in U\left(x^{*}, r_{3}\right)$, 
by using (4.8), (a3), (a4) and (4.11) we have that

$$
\begin{aligned}
& \left\|2 I-F^{\prime}\left(x_{0}\right)^{-1}\left[z_{0}, y_{0} ; F\right]\right\| \leq 1+\left\|F^{\prime}\left(x_{0}\right)^{-1}\left(F^{\prime}\left(x_{0}\right)-\left[z_{0}, y_{0} ; F\right]\right)\right\| \\
& \leq 1+\left\|F^{\prime}\left(x_{0}\right)^{-1} F^{\prime}\left(x^{*}\right)\right\|\left\|F^{\prime}\left(x^{*}\right)^{-1}\left(F^{\prime}\left(x_{0}\right)-\left[z_{0}, y_{0} ; F\right]\right)\right\| \\
& \leq 1+\left\|F^{\prime}\left(x_{0}\right)^{-1} F^{\prime}\left(x^{*}\right)\right\|\left\|F^{\prime}\left(x^{*}\right)^{-1}\left(F^{\prime}\left(x_{0}\right)-F\left(x^{*}\right)+F^{\prime}\left(x^{*}\right)-\left[z_{0}, y_{0} ; F\right]\right)\right\| \\
& \leq 1+\left\|F^{\prime}\left(x_{0}\right)^{-1} F^{\prime}\left(x^{*}\right)\right\|\left(\left\|F^{\prime}\left(x^{*}\right)^{-1}\left(F^{\prime}\left(x_{0}\right)-F\left(x^{*}\right)\right)\right\|\right. \\
& \left.\quad+\left\|F^{\prime}\left(x^{*}\right)^{-1}\left(F^{\prime}\left(x^{*}\right)-\left[z_{0}, y_{0} ; F\right]\right)\right\|\right) \\
& \quad 1+\frac{1}{1-w_{0}\left(\left\|x_{0}-x^{*}\right\|\right)}\left(w_{0}\left(\left\|x_{0}-x^{*}\right\|\right)+v_{0}\left(\left\|z_{0}-x^{*}\right\|+\left\|y_{0}-x^{*}\right\|\right)\right) \\
& \leq 1+\frac{w_{0}\left(\left\|x_{0}-x^{*}\right\|\right)+v_{0}\left(\left(g_{2}\left(\left\|x_{0}-x^{*}\right\|\right)+g_{1}\left(\left\|x_{0}-x^{*}\right\|\right)\right)\left\|x_{0}-x^{*}\right\|\right)}{1-w_{0}\left(\left\|x_{0}-x^{*}\right\|\right)} \\
& =p\left(\left\|x_{0}-x^{*}\right\|\right) .
\end{aligned}
$$

Notice that $\left\|x^{*}+\theta\left(x_{0}-x^{*}\right)-x^{*}\right\|=\theta\left\|x_{0}-x^{*}\right\|<r_{3}$ for each $\theta \in[0,1]$. That is $x^{*}+\theta\left(x_{0}-x^{*}\right) \in U\left(x^{*}, r_{3}\right)$. We can write

$$
F\left(x_{0}\right)=F\left(x_{0}\right)-F\left(x^{*}\right)=\int_{0}^{1} F^{\prime}\left(x^{*}+\theta\left(x_{0}-x^{*}\right)\right)\left(x_{0}-x^{*}\right) d \theta .
$$

By using (a6), we get that

$$
\begin{aligned}
\left\|F^{\prime}\left(x^{*}\right)^{-1} F\left(x_{0}\right)\right\| & =\left\|\int_{0}^{1} F^{\prime}\left(x^{*}\right)^{-1} F^{\prime}\left(x^{*}+\theta\left(x_{0}-x^{*}\right)\right)\left(x_{0}-x^{*}\right) d \theta\right\| \\
& \leq M\left\|x_{0}-x^{*}\right\| .
\end{aligned}
$$

Similarly, we obtain that

$$
\begin{aligned}
& \left\|F^{\prime}\left(x^{*}\right)^{-1} F\left(y_{0}\right)\right\| \leq M\left\|y_{0}-x^{*}\right\| . \\
& \left\|F^{\prime}\left(x^{*}\right)^{-1} F\left(z_{0}\right)\right\| \leq M\left\|z_{0}-x^{*}\right\| .
\end{aligned}
$$

Moreover, $x_{1}$ is well defined by the third substep of method (2.1) for $n=0$. Using (4.3) (for $i=3),(4.8),(4.11),(4.12)$, and (4.14), we obtain in turn that

$$
\begin{gathered}
\left\|x_{1}-x^{*}\right\| \leq\left\|z_{0}-x^{*}\right\|+\left\|2 I-F^{\prime}\left(x_{0}\right)^{-1}\left[z_{0}, y_{0} ; F\right]\right\|\left\|F^{\prime}\left(x_{0}\right)^{-1} F\left(z_{0}\right)\right\| \\
\leq\left\|z_{0}-x^{*}\right\|+p\left(\left\|x_{0}-x^{*}\right\|\right)\left\|F^{\prime}\left(x_{0}\right)^{-1} F^{\prime}\left(x^{*}\right)\right\|\left\|F^{\prime}\left(x^{*}\right)^{-1} F\left(z_{0}\right)\right\| \\
\leq\left\|z_{0}-x^{*}\right\|+\frac{M p\left(\left\|x_{0}-x^{*}\right\|\right)\left\|z_{0}-x^{*}\right\|}{1-w_{0}\left(\left\|x_{0}-x^{*}\right\|\right)} \leq\left(1+\frac{M p\left(\left\|x_{0}-x^{*}\right\|\right)}{1-w_{0}\left(\left\|x_{0}-x^{*}\right\|\right)}\right) \\
\quad \times\left\|z_{0}-x^{*}\right\| \leq g_{3}\left(\left\|x_{0}-x^{*}\right\|\right)\left\|x_{0}-x^{*}\right\| \leq\left\|x_{0}-x^{*}\right\|<r_{3},
\end{gathered}
$$

which shows (4.6) for $n=0$ and $x_{1} \in U\left(x^{*}, r_{3}\right)$. The induction for estimates (4.4)-(4.6) is completed by simply replacing $x_{0}, y_{0}, z_{0}, x_{1}$ by $x_{j}, y_{j}, z_{j}, x_{j+1}$ in the preceding estimates. Then, from estimate

$$
\left\|x_{j+1}-x^{*}\right\| \leq c\left\|x_{j}-x^{*}\right\|<r_{3}, \text { where } c=g_{3}\left(\left\|x_{0}-x^{*}\right\|\right) \in[0,1),
$$


we deduce that $\lim _{j \rightarrow \infty} x_{j}=x^{*}$ and $x_{j+1} \in U\left(x^{*}, r_{3}\right)$.

The uniqueness part is shown using (a3) and (a7) as follows. Define operator $Q$ by $Q=\int_{0}^{1} F^{\prime}\left(x^{* *}+\theta\left(x^{*}-x^{* *}\right)\right) d \theta$ for some $x^{* *} \in \Omega_{1}$ with $F\left(x^{* *}\right)=0$. Then, we have that

$$
\left\|F^{\prime}\left(x^{*}\right)^{-1}\left(Q-F^{\prime}\left(x^{*}\right)\right)\right\| \leq \int_{0}^{1} w_{0}\left(\theta\left\|x^{*}-x^{* *}\right\|\right) d \theta \leq \int_{0}^{1} w_{0}\left(\theta r^{*}\right) d \theta<1,
$$

so $Q^{-1} \in \mathcal{L}\left(B_{2}, B_{1}\right)$. Then, from the identity

$$
0=F\left(x^{*}\right)-F\left(x^{* *}\right)=Q\left(x^{*}-x^{* *}\right),
$$

we conclude that $x^{*}=x^{* *}$.

Next, we present the local convergence analysis of method (3.1) along the same lines of method (2.1). Define functions $\bar{g}_{2}, \lambda, \mu_{k}$ and $h_{k}$ on the interval $\left[0, r_{2}\right)$ by

$$
\bar{g}_{2}(t)=\frac{p(t)}{1-w_{0}(t)}, \lambda(t)=1+\bar{g}_{2}(t) M, \mu_{k}(t)=\lambda^{k}(t) g_{2}(t) t^{\lambda-1}, h_{k}(t)=\mu_{k}(t)-1 .
$$

We have that $h_{k}(0)<0$. Suppose that

$$
\mu_{k}(t) \rightarrow+\infty \text { or a positive number as } t \rightarrow r_{2}^{-} .
$$

Denote by $r^{(k)}$ the smallest zero of function $h_{k}$ on the interval $\left(0, r_{2}\right)$. Define the radius of convergence $r^{*}$ by $r^{*}=\min \left\{r_{1}, r^{(k)}\right\}$. Denote by $\left(A^{\prime}\right)$ the conditions (A) but with $r^{*}$ replacing $r_{3}$ together with condition (4.15).

Proposition 1. Suppose that the conditions $\left(A^{\prime}\right)$ hold. Then, sequence $\left\{x_{n}\right\}$ generated for $x_{0} \in U\left(x^{*}, r^{*}\right)-\left\{x^{*}\right\}$ by method (3.1) is well defined in $U\left(x^{*}, r^{*}\right)$, remains in $U\left(x^{*}, r^{*}\right)$ and converges to $x^{*}$. Moreover, the following estimates hold

$$
\begin{aligned}
& \left\|y_{n}-x^{*}\right\| \leq g_{1}\left(\left\|x_{n}-x^{*}\right\|\right)\left\|x_{n}-x^{*}\right\| \leq\left\|x_{n}-x^{*}\right\|<r^{*} \\
& \left\|z_{n}-x^{*}\right\| \leq g_{2}\left(\left\|x_{n}-x^{*}\right\|\right)\left\|x_{n}-x^{*}\right\|^{\lambda} \leq\left\|x_{n}-x^{*}\right\|, \\
& \left\|z_{n}^{(i)}-x^{*}\right\| \leq \lambda^{i}\left(\left\|x_{n}-x^{*}\right\|\right)\left\|z_{n}-x^{*}\right\| \leq \lambda^{i}\left(\left\|x_{n}-x^{*}\right\|\right) \\
& \quad \times g_{2}\left(\left\|x_{n}-x^{*}\right\|\right)\left\|x_{n}-x^{*}\right\|^{\lambda} \leq\left\|x_{n}-x^{*}\right\|, \quad i=1,2, \ldots, k-1, \\
& \left\|x_{n+1}-x^{*}\right\|=\left\|z_{n}^{(k)}-x^{*}\right\| \leq \lambda^{k}\left(\left\|x_{n}-x^{*}\right\|\right)\left\|z_{n}-x^{*}\right\| \\
& \quad \leq \mu_{k}\left(\left\|x_{n}-x^{*}\right\|\right)\left\|x_{n}-x^{*}\right\|,
\end{aligned}
$$

where the functions $\lambda$ and $\mu$ are defined previously. Furthermore, the vector $x^{*}$ is the only solution of equation $F(x)=0$ in $\Omega_{1}$.

Proof. We shall only show new estimates (4.16) and (4.17). Using the proof of Theorem 3, we show the first two estimates. Then, we can obtain that

$$
\begin{aligned}
\left\|\psi\left(x_{n}, y_{n}\right) F^{\prime}\left(x^{*}\right)\right\| & \leq\left\|\left(2 I-F^{\prime}\left(x_{n}\right)^{-1}\left[z_{n}, y_{n} ; F\right]\right) F^{\prime}\left(x_{n}\right)^{-1} F^{\prime}\left(x^{*}\right)\right\| \\
& \leq\left\|\left(2 I-F^{\prime}\left(x_{n}\right)^{-1}\left[z_{n}, y_{n} ; F\right]\right)\right\|\left\|F^{\prime}\left(x_{n}\right)^{-1} F^{\prime}\left(x^{*}\right)\right\| \\
& \leq \frac{p\left(\left\|x_{n}-x^{*}\right\|\right)}{1-w_{0}\left(\left\|x_{n}-x^{*}\right\|\right)} \leq \bar{g}_{2}\left(\left\|x_{n}-x^{*}\right\|\right) .
\end{aligned}
$$


Moreover, we have in turn the estimates

$$
\begin{aligned}
& \left\|z_{n}^{(1)}-x^{*}\right\|=\left\|z_{n}-x^{*}-\psi\left(x_{n}, y_{n}\right) F\left(z_{n}\right)\right\| \leq\left\|z_{n}-x^{*}\right\| \\
& \quad+\left\|\psi\left(x_{n}, y_{n}\right) F^{\prime}\left(x^{*}\right)\right\|\left\|F^{\prime}\left(x^{*}\right)^{-1} F\left(z_{n}\right)\right\| \\
& \leq\left\|z_{n}-x^{*}\right\|+\bar{g}_{2}\left(\left\|x_{n}-x^{*}\right\|\right) M\left\|z_{n}-x^{*}\right\| \\
& \leq \lambda\left(\left\|x_{n}-x^{*}\right\|\right)\left\|z_{n}-x^{*}\right\| \leq \mu_{1}\left(\left\|x_{n}-x^{*}\right\|\right)\left\|x_{n}-x^{*}\right\| .
\end{aligned}
$$

Similarly, we get that

$$
\begin{aligned}
\left\|z_{n}^{(2)}-x^{*}\right\| & \leq \lambda\left(\left\|x_{n}-x^{*}\right\|\right)\left\|z_{n}^{(1)}-x^{*}\right\| \leq \lambda^{2}\left(\left\|x_{n}-x^{*}\right\|\right)\left\|z_{n}-x^{*}\right\|, \\
& \ldots \ldots \ldots \ldots \ldots \ldots \\
\left\|z_{n}^{(i)}-x^{*}\right\| & \leq \lambda^{i}\left(\left\|x_{n}-x^{*}\right\|\right)\left\|z_{n}-x^{*}\right\| \\
\left\|x_{n+1}-x^{*}\right\| & =\left\|z_{n}^{(k)}-x^{*}\right\| \leq \lambda^{k}\left(\left\|x_{n}-x^{*}\right\|\right)\left\|z_{n}-x^{*}\right\| \\
& \leq \mu_{k}\left(\left\|x_{n}-x^{*}\right\|\right)\left\|x_{n}-x^{*}\right\| .
\end{aligned}
$$

That is we have $x_{n}, z_{n}, z_{n}^{(i)} \in U\left(x^{*}, r^{*}\right), i=1,2, \ldots, k$ and

$$
\left\|x_{n+1}-x^{*}\right\| \leq \bar{c}\left\|x_{n}-x^{*}\right\|
$$

where $\bar{c}=\mu_{k}\left(\left\|x_{0}-x^{*}\right\|\right) \in[0,1)$, so $\lim _{n \rightarrow \infty} x_{n}=x^{*}$ and $x_{n+1} \in U\left(x^{*}, r^{*}\right)$.

Remark 1. It is worth noticing that the methods (2.1) and (3.1) will not change on using the conditions of Theorem 3 instead of stronger conditions used in Theorems 1 and 2. Moreover, we can compute the computational order of convergence (COC) [15] defined by

$$
\mathrm{COC}=\ln \left(\frac{\left\|x_{n+1}-x^{*}\right\|}{\left\|x_{n}-x^{*}\right\|}\right) / \ln \left(\frac{\left\|x_{n}-x^{*}\right\|}{\left\|x_{n-1}-x^{*}\right\|}\right), \quad n=1,2, \ldots .
$$

or the approximate computational order of convergence (ACOC) [6], given by

$$
\mathrm{ACOC}=\ln \left(\frac{\left\|x_{n+1}-x_{n}\right\|}{\left\|x_{n}-x_{n-1}\right\|}\right) / \ln \left(\frac{\left\|x_{n}-x_{n-1}\right\|}{\left\|x_{n-1}-x_{n-2}\right\|}\right) . \quad n=1,2, \ldots
$$

This way we obtain in practice the order of convergence.

Remark 2. Numerous choices for function $\varphi^{(p)}$ are possible. Let us choose, e.g.

$$
\begin{aligned}
& \varphi^{(3)}\left(x_{n}, y_{n}\right)=y_{n}-F^{\prime}\left(x_{n}\right)^{-1} F\left(y_{n}\right), \\
& \varphi^{(4)}\left(x_{n}, y_{n}\right)=y_{n}-\left(3 I-2 F^{\prime}\left(x_{n}\right)^{-1}\left[y_{n}, x_{n} ; F\right]\right) F^{\prime}\left(x_{n}\right)^{-1} F\left(y_{n}\right),
\end{aligned}
$$

which are third and fourth order iteration functions, respectively. Let us discuss the cases separately. 
Corollary 1. For the choice $\varphi^{(3)}\left(x_{n}, y_{n}\right)$ we can have as in (4.8), (4.10) and (4.13) that

$$
\begin{aligned}
\| z_{n} & -x^{*}\|\leq\| y_{n}-x^{*}\|+\| F\left(x_{n}\right)^{-1} F^{\prime}\left(x^{*}\right)\|\| F\left(x^{*}\right)^{-1} F^{\prime}\left(y_{n}\right)\|\leq\| y_{n}-x^{*} \| \\
& +\frac{M\left\|y_{n}-x^{*}\right\|}{1-w_{0}\left(\left\|x_{n}-x^{*}\right\|\right)} \leq\left(1+\frac{M}{1-w_{0}\left(\left\|x_{n}-x^{*}\right\|\right)}\right)\left\|y_{n}-x^{*}\right\| \\
\leq & \left(1+\frac{M}{1-w_{0}\left(\left\|x_{n}-x^{*}\right\|\right)}\right) g_{1}\left(\left\|x_{n}-x^{*}\right\|\right)\left\|x_{n}-x^{*}\right\| \\
\leq & g_{2}\left(\left\|x_{n}-x^{*}\right\|\right)\left\|x_{n}-x^{*}\right\| .
\end{aligned}
$$

So, we can choose

$$
g_{2}(t)=\left(1+\frac{M}{1-w_{0}(t)}\right) g_{1}(t) \text { and } \lambda=1
$$

Corollary 2. We consider the choice $\varphi^{(4)}\left(x_{n}, y_{n}\right)$. Let us take linear operator $A=3 I-2 F^{\prime}\left(x_{n}\right)^{-1}\left[y_{n}, x_{n} ; F\right]$, then by using (2.1), (4.8), (a3) and (a4) we obtain that

$$
\begin{aligned}
& \|A\| \leq 1+\left\|2 F^{\prime}\left(x_{n}\right)^{-1}\left(F^{\prime}\left(x_{n}\right)-\left[y_{n}, x_{n} ; F\right]\right)\right\| \\
& \leq 1+2\left\|F^{\prime}\left(x_{n}\right)^{-1} F^{\prime}\left(x^{*}\right)\right\|\left(\left\|F^{\prime}\left(x^{*}\right)^{-1}\left(F^{\prime}\left(x_{n}\right)-F^{\prime}\left(x^{*}\right)\right)\right\|\right. \\
& \left.+\left\|F^{\prime}\left(x^{*}\right)^{-1}\left(F^{\prime}\left(x^{*}\right)-\left[y_{n}, x_{n} ; F\right]\right)\right\|\right) \leq 1+\frac{2}{1-w_{0}\left(\left\|x_{n}-x^{*}\right\|\right)} \\
& \times\left(w_{0}\left(\left\|x_{n}-x^{*}\right\|\right)+v_{0}\left(\left\|x_{n}-x^{*}\right\|+\left\|y_{n}-x^{*}\right\|\right)\right) \leq 1+\frac{2}{1-w_{0}\left\|x_{n}-x^{*}\right\|} \\
& \times\left(w_{0}\left(\left\|x_{n}-x^{*}\right\|\right)+v_{0}\left(\left(1+g_{1}\left(\left\|x_{n}-x^{*}\right\|\right)\right)\left\|x_{n}-x^{*}\right\|\right)\right)=q\left(\left\|x_{n}-x^{*}\right\|\right) .
\end{aligned}
$$

Using the second step of method (2.1), (4.8), (4.10), (4.13) and (4.20), we obtain that

$$
\begin{aligned}
& \left\|z_{n}-x^{*}\right\| \leq\left\|y_{n}-x^{*}\right\|+\|A\|\left\|F^{\prime}\left(x_{n}\right)^{-1} F\left(y_{n}\right)\right\| \\
& =\left\|y_{n}-x^{*}\right\|+\|A\|\left\|F^{\prime}\left(x_{n}\right)^{-1} F\left(x^{*}\right)\right\|\left\|F^{\prime}\left(x^{*}\right)^{-1} F\left(y_{n}\right)\right\| \\
& \leq\left\|y_{n}-x^{*}\right\|+q\left(\left\|x_{n}-x^{*}\right\|\right) \frac{M\left\|y_{n}-x^{*}\right\|}{1-w_{0}\left(\left\|x_{n}-x^{*}\right\|\right)} \\
& \leq\left(1+\frac{M q\left(\left\|x_{n}-x^{*}\right\|\right)}{1-w_{0}\left(\left\|x_{n}-x^{*}\right\|\right)}\right)\left\|y_{n}-x^{*}\right\| \leq\left(1+\frac{M q\left(\left\|x_{n}-x^{*}\right\|\right)}{1-w_{0}\left(\left\|x_{n}-x^{*}\right\|\right)}\right) \\
& \quad \times g_{1}\left(\left\|x_{n}-x^{*}\right\|\right)\left\|x_{n}-x^{*}\right\| \leq g_{2}\left(\left\|x_{n}-x^{*}\right\|\right)\left\|x_{n}-x^{*}\right\| .
\end{aligned}
$$

So, we can choose $g_{2}(t)=\left(1+M q(t) /\left(1-w_{0}(t)\right)\right) g_{1}(t)$, where $q(t)=1+$ $2\left(w_{0}(t)+v_{0}\left(\left(1+g_{1}(t)\right) t\right)\right) /\left(1-w_{0}(t)\right)$ and $\lambda=1$.

\section{Computational efficiency}

Computational efficiency of an iterative method is measured by the efficiency index $E=p^{1 /(d+o p)}$ (see $[5,11]$ ), where $p$ is the order of convergence, $d$ is the 
number of function evaluations per iteration and $o p$ is the number of operations (i.e. products and quotients) required per iteration. The various evaluations and operations that contribute to the total cost of computation for a system of $m$ nonlinear equations in $m$ unknowns are as follows. When computing $F$ in any iterative function we evaluate $m$ scalar functions $f_{i},(1 \leqslant i \leqslant m)$ and for the computation of divided difference we use the formula (see [10])

$$
[x, y ; F]_{i j}=\frac{f_{i}\left(x_{1}, \ldots, x_{j}, y_{j+1}, \ldots, y_{m}\right)-f_{i}\left(x_{1}, \ldots, x_{j-1}, y_{j}, \ldots, y_{m}\right)}{x_{j}-y_{j}},
$$

where $1 \leqslant i, j \leqslant m$. It requires $m(m-1)$ scalar functions, where $F(x)$ and $F(y)$ are computed separately. Furthermore, we have to add $m^{2}$ quotients from any divided difference. In order to compute an inverse linear operator, a linear system is solved that requires $m(m-1)(2 m-1) / 6$ products and $m(m-1) / 2$ quotients in the LU decomposition, and $m(m-1)$ products and $m$ quotients in the resolution of two triangular linear systems. Moreover, we add $m^{2}$ products for the multiplication of a matrix with a vector or of a matrix by a scalar and $m$ products for the multiplication of a vector by a scalar.

In order to compare the computational efficiency, we choose three- and fourstep methods of the family (3.1) with the base as two-step methods (4.18) and (4.19) of order three and four, respectively. The corresponding methods are denoted by $\mathrm{M}_{5,1}, \mathrm{M}_{6,1}, \mathrm{M}_{7,1}$ and $\mathrm{M}_{8,1}$, wherein $\mathrm{M}_{p, i}$ denotes an $i$ th iterative method of order $p$. Comparison is performed with existing sixth order methods by Behl et al. [4], Esmaeili-Ahmadi [8] and Grau et al. [10]. These methods are expressed as follows:

Sixth order methods by Grau et al. $\left(\mathrm{M}_{6,2}\right.$ and $\left.\mathrm{M}_{6,3}\right)$ :

$$
\begin{aligned}
& y_{n}=x_{n}-F^{\prime}\left(x_{n}\right)^{-1} F\left(x_{n}\right), \quad z_{n}=y_{n}-\left(2\left[y_{n}, x_{n} ; F\right]-F^{\prime}\left(x_{n}\right)\right)^{-1} F\left(y_{n}\right), \\
& x_{n+1}=z_{n}-\left(2\left[y_{n}, x_{n} ; F\right]-F^{\prime}\left(x_{n}\right)\right)^{-1} F\left(z_{n}\right)
\end{aligned}
$$

and

$$
\begin{aligned}
& y_{n}=x_{n}-F^{\prime}\left(x_{n}\right)^{-1} F\left(x_{n}\right), z_{n}=y_{n}-\left(2\left[y_{n}, x_{n} ; F\right]^{-1}-F^{\prime}\left(x_{n}\right)^{-1}\right) F\left(y_{n}\right), \\
& x_{n+1}=z_{n}-\left(2\left[y_{n}, x_{n} ; F\right]^{-1}-F^{\prime}\left(x_{n}\right)^{-1}\right) F\left(z_{n}\right) .
\end{aligned}
$$

Sixth order method by Esmaeili-Ahmadi $\left(\mathrm{M}_{6,4}\right)$ :

$$
\begin{aligned}
y_{n} & =x_{n}-F^{\prime}\left(x_{n}\right)^{-1} F\left(x_{n}\right), \\
z_{n} & =y_{n}+\frac{1}{3}\left(F^{\prime}\left(x_{n}\right)^{-1}+2\left(F^{\prime}\left(x_{n}\right)-3 F^{\prime}\left(y_{n}\right)\right)^{-1}\right) F\left(x_{n}\right), \\
x_{n+1} & =z_{n}+\frac{1}{3}\left(-F^{\prime}\left(x_{n}\right)^{-1}+4\left(F^{\prime}\left(x_{n}\right)-3 F^{\prime}\left(y_{n}\right)\right)^{-1}\right) F\left(z_{n}\right) .
\end{aligned}
$$

Sixth order method by Behl et al. $\left(\mathrm{M}_{6,5}\right)$ :

$$
\begin{aligned}
y_{n} & =x_{n}-a F^{\prime}\left(x_{n}\right)^{-1} F\left(x_{n}\right), \\
z_{n} & =y_{n}-\left(b F^{\prime}\left(x_{n}\right)^{-1}+\left(c F^{\prime}\left(x_{n}\right)+d F^{\prime}\left(y_{n}\right)\right)^{-1}\right) F\left(x_{n}\right), \\
x_{n+1} & =z_{n}-\left(g F^{\prime}\left(x_{n}\right)^{-1}+\left(e F^{\prime}\left(x_{n}\right)+h F^{\prime}\left(y_{n}\right)\right)^{-1}\right) F\left(z_{n}\right),
\end{aligned}
$$


where $a=\frac{2}{3}, b=-\frac{1}{6}, c=-1, d=3, g=\frac{1}{2}, e=-\frac{2 g+1}{2(g-1)^{2}}$ and $h=\frac{3}{2(g-1)^{2}}$.

Let us denote efficiency indices of the methods $\mathrm{M}_{p, i}$ by $\mathrm{E}_{p, i}$ and computational costs by $\mathrm{C}_{p, i}$ where $p$ is order of convergence and $i=1,2,3,4,5$. Computational cost and efficiency of various methods are expressed as:

$$
\begin{aligned}
\mathrm{C}_{5,1} & =\frac{1}{3} m^{3}+8 m^{2}+\frac{8}{3} m \text { and } \mathrm{E}_{5,1}=5^{1 / C_{5,1}} . \\
\mathrm{C}_{6,1} & =\frac{1}{3} m^{3}+12 m^{2}+\frac{11}{3} m \text { and } \mathrm{E}_{6,1}=6^{1 / C_{6,1}} . \\
\mathrm{C}_{6,2} & =\frac{2}{3} m^{3}+7 m^{2}+\frac{4}{3} m \text { and } \mathrm{E}_{6,2}=6^{1 / C_{6,2}} . \\
\mathrm{C}_{6,3} & =\frac{2}{3} m^{3}+8 m^{2}+\frac{10}{3} m \text { and } \mathrm{E}_{6,3}=6^{1 / C_{6,3}} . \\
\mathrm{C}_{6,4} & =\frac{2}{3} m^{3}+7 m^{2}+\frac{16}{3} m \text { and } \mathrm{E}_{6,4}=6^{1 / C_{6,4}} . \\
\mathrm{C}_{6,5} & =m^{3}+9 m^{2}+3 m \text { and } \mathrm{E}_{6,5}=6^{1 / C_{6,5}} . \\
\mathrm{C}_{7,1} & =\frac{1}{3} m^{3}+11 m^{2}+\frac{14}{3} m \text { and } \mathrm{E}_{7,1}=7^{1 / C_{7,1}} . \\
\mathrm{C}_{8,1} & =\frac{1}{3} m^{3}+15 m^{2}+\frac{17}{3} m \text { and } \mathrm{E}_{8,1}=8^{1 / C_{8,1}} .
\end{aligned}
$$

To compare the efficiency of considered iterative methods, say $\mathrm{M}_{p, i}$ against $\mathrm{M}_{q, j}$, we consider the ratio

$$
\mathrm{R}_{p, i ; q, j}=\frac{\log \mathrm{E}_{p, i}}{\log \mathrm{E}_{q, j}}=\frac{\mathrm{C}_{q, j} \log (p)}{\mathrm{C}_{p, i} \log (q)} .
$$

It is clear that when $\mathrm{R}_{p, i ; q, j}>1$, the iterative method $\mathrm{M}_{p, i}$ is more efficient than $\mathrm{M}_{q, j}$.

$\mathrm{M}_{5,1}$ versus $\mathrm{M}_{6,2}$ case: The ratio (5.2) is given by

$$
\mathrm{R}_{5,1 ; 6,2}=\frac{\left(\frac{2}{3} m^{3}+7 m^{2}+\frac{4}{3} m\right) \log (5)}{\left(\frac{1}{3} m^{3}+8 m^{2}+\frac{8}{3} m\right) \log (6)} .
$$

It is easy to prove that $\mathrm{R}_{5,1 ; 6,2}>1$ for $m \geqslant 8$. Thus, we conclude that $\mathrm{E}_{5,1}>\mathrm{E}_{6,2}$ for $m \geqslant 8$.

$\mathrm{M}_{5,1}$ versus $\mathrm{M}_{6,3}$ case: In this case the ratio (5.2) is given by

$$
\mathrm{R}_{5,1 ; 6,3}=\frac{\left(\frac{2}{3} m^{3}+8 m^{2}+\frac{10}{3} m\right) \log (5)}{\left(\frac{1}{3} m^{3}+8 m^{2}+\frac{8}{3} m\right) \log (6)} .
$$

It can be checked that $\mathrm{R}_{5,1 ; 6,3}>1$ for $m \geqslant 3$. Thus, we have that $\mathrm{E}_{5,1}>\mathrm{E}_{6,3}$ for $m \geqslant 3$.

$\mathrm{M}_{5,1}$ versus $\mathrm{M}_{6,4}$ case: In this case the ratio

$$
\mathrm{R}_{5,1 ; 6,4}=\frac{\left(\frac{2}{3} m^{3}+7 m^{2}+\frac{16}{3} m\right) \log (5)}{\left(\frac{1}{3} m^{3}+8 m^{2}+\frac{8}{3} m\right) \log (6)}>1,
$$


for $m \geqslant 5$, which implies that $\mathrm{E}_{5,1}>\mathrm{E}_{6,4}$ for $m \geqslant 5$.

$\mathrm{M}_{5,1}$ versus $\mathrm{M}_{6,5}$ case: Here the ratio

$$
\mathrm{R}_{5,1 ; 6,5}=\frac{\left(m^{3}+9 m^{2}+3 m\right) \log (5)}{\left(\frac{1}{3} m^{3}+8 m^{2}+\frac{8}{3} m\right) \log (6)}>1
$$

for $m \geqslant 2$ which implies that $\mathrm{E}_{5,1}>\mathrm{E}_{6,5}$ for $m \geqslant 2$.

$\mathrm{M}_{6,1}$ versus $\mathrm{M}_{5,1}$ case: Here the ratio

$$
\mathrm{R}_{6,1 ; 5,1}=\frac{\left(\frac{1}{3} m^{3}+8 m^{2}+\frac{8}{3} m\right) \log (6)}{\left(\frac{1}{3} m^{3}+12 m^{2}+\frac{11}{3} m\right) \log (5)}>1,
$$

for $m \geqslant 83$ which implies that $\mathrm{E}_{6,1}>\mathrm{E}_{5,1}$ for $m \geqslant 83$.

$\mathrm{M}_{6,1}$ versus $\mathrm{M}_{6,2}$ case: The ratio (5.2) is given by

$$
\mathrm{R}_{6,1 ; 6,2}=\frac{\frac{2}{3} m^{3}+7 m^{2}+\frac{4}{3} m}{\frac{1}{3} m^{3}+12 m^{2}+\frac{11}{3} m} .
$$

It is easy to prove that $\mathrm{R}_{6,1 ; 6,2}>1$ for $m \geqslant 16$. Thus, we conclude that $\mathrm{E}_{6,1}>\mathrm{E}_{6,2}$ for $m \geqslant 16$.

$\mathrm{M}_{6,1}$ versus $\mathrm{M}_{6,3}$ case: The ratio (5.2) is given by

$$
\mathrm{R}_{6,1 ; 6,3}=\frac{\frac{2}{3} m^{3}+8 m^{2}+\frac{10}{3} m}{\frac{1}{3} m^{3}+12 m^{2}+\frac{11}{3} m} .
$$

It can be checked that $\mathrm{R}_{6,1 ; 6,3}>1$ for $m \geqslant 13$. Thus, we have that $\mathrm{E}_{6,1}>\mathrm{E}_{6,3}$ for $m \geqslant 13$.

$\mathrm{M}_{6,1}$ versus $\mathrm{M}_{6,4}$ case: In this case the ratio

$$
\mathrm{R}_{6,1 ; 6,4}=\frac{\frac{2}{3} m^{3}+7 m^{2}+\frac{16}{3} m}{\frac{1}{3} m^{3}+12 m^{2}+\frac{11}{3} m}>1,
$$

for $m \geqslant 22$, which implies that $\mathrm{E}_{6,1}>\mathrm{E}_{6,4}$ for $m \geqslant 22$.

$\mathrm{M}_{6,1}$ versus $\mathrm{M}_{6,5}$ case: Here the ratio

$$
\mathrm{R}_{6,1 ; 6,5}=\frac{m^{3}+9 m^{2}+3 m}{\frac{1}{3} m^{3}+12 m^{2}+\frac{11}{3} m}>1,
$$

for $m \geqslant 5$ which implies that $\mathrm{E}_{6,1}>\mathrm{E}_{6,5}$ for $m \geqslant 5$.

$\mathrm{M}_{7,1}$ versus $\mathrm{M}_{5,1}$ case: Here the ratio

$$
\mathrm{R}_{7,1 ; 5,1}=\frac{\left(\frac{1}{3} m^{3}+8 m^{2}+\frac{8}{3} m\right) \log (7)}{\left(\frac{1}{3} m^{3}+11 m^{2}+\frac{14}{3} m\right) \log (5)}>1
$$


for $m \geqslant 21$ which implies that $\mathrm{E}_{7,1}>\mathrm{E}_{5,1}$ for $m \geqslant 21$.

$\mathrm{M}_{7,1}$ versus $\mathrm{M}_{6,1}$ case: Here the ratio

$$
\mathrm{R}_{7,1 ; 6,1}=\frac{\left(\frac{1}{3} m^{3}+12 m^{2}+\frac{11}{3} m\right) \log (7)}{\left(\frac{1}{3} m^{3}+11 m^{2}+\frac{14}{3} m\right) \log (6)}>1
$$

for $m \geqslant 2$ which implies that $\mathrm{E}_{7,1}>\mathrm{E}_{6,1}$ for $m \geqslant 2$.

$\mathrm{M}_{7,1}$ versus $\mathrm{M}_{6,2}$ case: The ratio (5.2) is given by

$$
\mathrm{R}_{7,1 ; 6,2}=\frac{\left(\frac{2}{3} m^{3}+7 m^{2}+\frac{4}{3} m\right) \log (7)}{\left(\frac{1}{3} m^{3}+11 m^{2}+\frac{14}{3} m\right) \log (6)} .
$$

It is easy to prove that $R_{7,1 ; 6,2}>1$ for $m \geqslant 10$. Thus, we conclude that $\mathrm{E}_{7,1}>\mathrm{E}_{6,2}$ for $m \geqslant 10$.

$M_{7,1}$ versus $M_{6,3}$ case: The ratio (5.2) is given by

$$
\mathrm{R}_{7,1 ; 6,3}=\frac{\left(\frac{2}{3} m^{3}+8 m^{2}+\frac{10}{3} m\right) \log (7)}{\left(\frac{1}{3} m^{3}+11 m^{2}+\frac{14}{3} m\right) \log (6)} .
$$

It can be checked that $\mathrm{R}_{7,1 ; 6,3}>1$ for $m \geqslant 7$. Thus, we have that $\mathrm{E}_{7,1}>\mathrm{E}_{6,3}$ for $m \geqslant 7$.

$\mathrm{M}_{7,1}$ versus $\mathrm{M}_{6,4}$ case: In this case the ratio

$$
\mathrm{R}_{7,1 ; 6,4}=\frac{\left(\frac{2}{3} m^{3}+7 m^{2}+\frac{16}{3} m\right) \log (7)}{\left(\frac{1}{3} m^{3}+11 m^{2}+\frac{14}{3} m\right) \log (6)}>1
$$

for $m \geqslant 9$, which implies that $\mathrm{E}_{7,1}>\mathrm{E}_{6,4}$ for $m \geqslant 9$.

$\mathrm{M}_{7,1}$ versus $\mathrm{M}_{6,5}$ case: Here the ratio

$$
\mathrm{R}_{7,1 ; 6,5}=\frac{\left(m^{3}+9 m^{2}+3 m\right) \log (7)}{\left(\frac{1}{3} m^{3}+11 m^{2}+\frac{14}{3} m\right) \log (6)}>1,
$$

for $m \geqslant 3$ which implies that $\mathrm{E}_{7,1}>\mathrm{E}_{6,5}$ for $m \geqslant 3$.

$\mathrm{M}_{8,1}$ versus $\mathrm{M}_{5,1}$ case: Here the ratio

$$
\mathrm{R}_{8,1 ; 5,1}=\frac{\left(\frac{1}{3} m^{3}+8 m^{2}+\frac{8}{3} m\right) \log (8)}{\left(\frac{1}{3} m^{3}+15 m^{2}+\frac{17}{3} m\right) \log (5)}>1
$$

for $m \geqslant 49$ which implies that $\mathrm{E}_{8,1}>\mathrm{E}_{5,1}$ for $m \geqslant 49$.

$\mathrm{M}_{8,1}$ versus $\mathrm{M}_{6,1}$ case: Here the ratio

$$
\mathrm{R}_{8,1 ; 6,1}=\frac{\left(\frac{1}{3} m^{3}+12 m^{2}+\frac{11}{3} m\right) \log (8)}{\left(\frac{1}{3} m^{3}+15 m^{2}+\frac{17}{3} m\right) \log (6)}>1
$$


for $m \geqslant 22$ which implies that $\mathrm{E}_{8,1}>\mathrm{E}_{6,1}$ for $m \geqslant 22$.

$\mathrm{M}_{8,1}$ versus $\mathrm{M}_{6,2}$ case: The ratio (5.2) is given by

$$
\mathrm{R}_{8,1 ; 6,2}=\frac{\left(\frac{2}{3} m^{3}+7 m^{2}+\frac{4}{3} m\right) \log (8)}{\left(\frac{1}{3} m^{3}+15 m^{2}+\frac{17}{3} m\right) \log (6)} .
$$

It is easy to prove that $\mathrm{R}_{8,1 ; 6,2}>1$ for $m \geqslant 17$. Thus, we conclude that $\mathrm{E}_{8,1}>\mathrm{E}_{6,2}$ for $m \geqslant 17$.

$\mathrm{M}_{8,1}$ versus $\mathrm{M}_{6,3}$ case: The ratio (5.2) is given by

$$
\mathrm{R}_{8,1 ; 6,3}=\frac{\left(\frac{2}{3} m^{3}+8 m^{2}+\frac{10}{3} m\right) \log (8)}{\left(\frac{1}{3} m^{3}+15 m^{2}+\frac{17}{3} m\right) \log (6)} .
$$

It can be checked that $\mathrm{R}_{8,1 ; 6,3}>1$ for $m \geqslant 14$. Thus, we have that $\mathrm{E}_{8,1}>\mathrm{E}_{6,3}$ for $m \geqslant 14$.

$\mathrm{M}_{8,1}$ versus $\mathrm{M}_{6,4}$ case: In this case the ratio

$$
\mathrm{R}_{8,1 ; 6,4}=\frac{\left(\frac{2}{3} m^{3}+7 m^{2}+\frac{16}{3} m\right) \log (8)}{\left(\frac{1}{3} m^{3}+15 m^{2}+\frac{17}{3} m\right) \log (6)}>1,
$$

for $m \geqslant 16$, which implies that $\mathrm{E}_{8,1}>\mathrm{E}_{6,4}$ for $m \geqslant 16$.

$\mathrm{M}_{8,1}$ versus $\mathrm{M}_{6,5}$ case: The ratio

$$
\mathrm{R}_{8,1 ; 6,5}=\frac{\left(m^{3}+9 m^{2}+3 m\right) \log (8)}{\left(\frac{1}{3} m^{3}+15 m^{2}+\frac{17}{3} m\right) \log (6)}>1,
$$

for $m \geqslant 6$ which implies that $\mathrm{E}_{8,1}>\mathrm{E}_{6,5}$ for $m \geqslant 6$.

$M_{8,1}$ versus $M_{7,1}$ case: Here the ratio

$$
\mathrm{R}_{8,1 ; 7,1}=\frac{\left(\frac{1}{3} m^{3}+11 m^{2}+\frac{14}{3} m\right) \log (8)}{\left(\frac{1}{3} m^{3}+15 m^{2}+\frac{17}{3} m\right) \log (7)}>1,
$$

for $m \geqslant 143$ which implies that $\mathrm{E}_{8,1}>\mathrm{E}_{7,1}$ for $m \geqslant 143$.

The above results are summarized in the following theorem:

Theorem 4. We have that: (a) $E_{5,1}>\left\{E_{6,2}, E_{6,3}, E_{6,4}, E_{6,5}\right\}$ for $m \geqslant 8$, $m \geqslant 3, m \geqslant 5, m \geqslant 2$, respectively;

(b) $E_{6,1}>\left\{E_{5,1}, E_{6,2}, E_{6,3}, E_{6,4}, E_{6,5}\right\}$ for $m \geqslant 83, m \geqslant 16, m \geqslant 13, m \geqslant$ $22, m \geqslant 5$, respectively;

(c) $E_{7,1}>\left\{E_{5,1}, E_{6,1}, E_{6,2}, E_{6,3}, E_{6,4}, E_{6,5}\right\}$ for $m \geqslant 21, m \geqslant 2, m \geqslant$ $10, m \geqslant 7, m \geqslant 9, m \geqslant 3$, respectively.

(d) $E_{8,1}>\left\{E_{5,1}, E_{6,1}, E_{6,2}, E_{6,3}, E_{6,4}, E_{6,5}, E_{7,1}\right\}$ for $m \geqslant 49, m \geqslant 22, m \geqslant$ $17, m \geqslant 14, m \geqslant 16, m \geqslant 6, m \geqslant 143$, respectively. 


\section{Numerical examples}

Here, we shall demonstrate the theoretical results which we have proved in Section 3. As in the previous Section, the methods of the family (3.1) chosen, with the choices $\varphi^{(p)}\left(x_{n}, y_{n}\right)$ where $p=3,4$ as given by (4.18) and (4.19), are of order five, six, seven and eight that we denote by $M_{5,1}, M_{6,1}, M_{7,1}$ and $M_{8,1}$, respectively. We consider three numerical examples, which are defined as follows:

Example 1. Suppose that the motion of an object in three dimensions is governed by system of differential equations

$$
f_{1}^{\prime}(x)-f_{1}(x)-1=0, \quad f_{2}^{\prime}(y)-(e-1) y-1=0, \quad f_{3}^{\prime}(z)-1=0,
$$

with $x, y, z \in \Omega$ for $f_{1}(0)=f_{2}(0)=f_{3}(0)=0$. Then, the solution of the system is given for $u=(x, y, z)^{T}$ by function $F:=\left(f_{1}, f_{2}, f_{3}\right): \Omega \rightarrow \mathbb{R}^{3}$ defined by $F(u)=\left(e^{x}-1, \frac{e-1}{2} y^{2}+y, z\right)^{T}$. The Fréchet-derivative is given by

$$
F^{\prime}(u)=\left[\begin{array}{ccc}
e^{x} & 0 & 0 \\
0 & (e-1) y+1 & 0 \\
0 & 0 & 1
\end{array}\right]
$$

Then for $x^{*}=(0,0,0)^{T}$, we deduce that $w_{0}(t)=L_{0} t, w(t)=L t$ and $v_{0}(t)=M$, where $L_{0}=e-1<L=e^{\frac{1}{L_{0}}}=1.7896$ and $M=e^{\frac{1}{L_{0}}}=1.7896$. The parameters are displayed in Table 1.

Table 1. Numerical results for example 1

\begin{tabular}{rrrr}
\hline$M_{5,1}$ & $M_{6,1}$ & $M_{7,1}$ & $M_{8,1}$ \\
\hline$r_{1}=0.382733$ & $r_{1}=0.382733$ & $r_{1}=0.382733$ & $r_{1}=0.382733$ \\
$r^{(1)}=0.041392$ & $r^{(1)}=0.059457$ & $r^{(2)}=0.007138$ & $r^{(2)}=0.024531$ \\
$r^{*}=0.041392$ & $r^{*}=0.059457$ & $r^{*}=0.007138$ & $r^{*}=0.024531$ \\
\hline
\end{tabular}

Example 2. Let $B_{1}=B_{2}=C[0,1]$, be the space of continuous functions defined on the interval $[0,1]$ and be equipped with max norm. Let $\Omega=\bar{U}(0,1)$. Define function $F$ on $\Omega$ by $F(\varphi)(x)=\phi(x)-10 \int_{0}^{1} x \theta \varphi(\theta)^{3} d \theta$. We have that

$$
F^{\prime}(\varphi(\xi))(x)=\xi(x)-30 \int_{0}^{1} x \theta \varphi(\theta)^{2} \xi(\theta) d \theta, \text { for each } \xi \in \Omega .
$$

Then for $x^{*}=0$ we have that $L_{0}=15, L=30$ and $v_{0}(t)=M=2$. The parameters are displayed in Table 2.

Example 3. Let us consider the function $F:=\left(f_{1}, f_{2}, f_{3}\right): \Omega \rightarrow \mathbb{R}^{3}$ defined by

$$
F(x)=\left(10, x_{1}+\sin \left(x_{1}+x_{2}\right)-1,8 x_{2}-\cos ^{2}\left(x_{3}-x_{2}\right)-1,12 x_{3}+\sin \left(x_{3}\right)-1\right)^{T},
$$


Table 2. Numerical results for example 2

\begin{tabular}{rrrr}
\hline$M_{5,1}$ & $M_{6,1}$ & $M_{7,1}$ & $M_{8,1}$ \\
\hline$r_{1}=0.033333$ & $r_{1}=0.033333$ & $r_{1}=0.033333$ & $r_{1}=0.033333$ \\
$r^{(1)}=0.002751$ & $r^{(1)}=0.000816$ & $r^{(2)}=0.000438$ & $r^{(2)}=0.000122$ \\
$r^{*}=0.002751$ & $r^{*}=0.000816$ & $r^{*}=0.000438$ & $r^{*}=0.000122$ \\
\hline
\end{tabular}

where $x=\left(x_{1}, x_{2}, x_{3}\right)^{T}$. The Fréchet-derivative is given by

$$
F^{\prime}(x)=\left[\begin{array}{ccc}
10+\cos \left(x_{1}+x_{2}\right) & \cos \left(x_{1}+x_{2}\right) & 0 \\
0 & 8+\sin 2\left(x_{2}-x_{3}\right) & -2 \sin \left(x_{2}-x_{3}\right) \\
0 & 0 & 12+\cos \left(x_{3}\right)
\end{array}\right]
$$

Then for $x^{*}=\{0.0689 \ldots, 0.2464 \ldots, 0.0769 \ldots\}^{T}$ we have that $L_{0}=L=$ $0.269812, v_{0}(t)=2$ and $M=13.0377$. In this case the calculated values of parameters are given in Table 3 .

Table 3. Numerical results for example 3

\begin{tabular}{rrrr}
\hline$M_{5,1}$ & $M_{6,1}$ & $M_{7,1}$ & $M_{8,1}$ \\
\hline$r_{1}=2.470856$ & $r_{1}=2.470856$ & $r_{1}=2.470856$ & $r_{1}=2.470856$ \\
$r^{(1)}=0.012985$ & $r^{(1)}=0.002781$ & $r^{(2)}=0.000328$ & $r^{(2)}=0.000069$ \\
$r^{*}=0.012985$ & $r^{*}=0.002781$ & $r^{*}=0.000328$ & $r^{*}=0.000069$ \\
\hline
\end{tabular}

\section{Applications}

We apply the methods $M_{5,1}, M_{6,1}, M_{7,1}$ and $M_{8,1}$ of the proposed family (3.1) to solve systems of nonlinear equations in $\mathbb{R}^{m}$. A comparison between the performance of present methods with existing methods $M_{6,2}, M_{6,3}, M_{6,4}$ and $M_{6,5}$ is also shown. Computations are performed in the programming package Mathematica [16] using multiple-precision arithmetic. For every problem considered below, we record the number of iterations $(n)$ needed to converge to the solution such that the stopping criterion $\left\|x_{n+1}-x_{n}\right\|+\left\|F\left(x_{n}\right)\right\|<10^{-200}$ is satisfied. Divided difference $[x, y ; F]$ used in the methods is computed by the formula given in (5.1). Solutions are displayed to four decimal places and after that the dots are shown to express non terminating nature of the figures. Following problems are chosen for numerical tests:

Problem 1. Consider the system of nonlinear equations (selected from [14])

$$
\sum_{j=1, j \neq i}^{m} x_{j}-e^{-x_{i}}=0,1 \leq i \leq m
$$

with initial value $x^{(0)}=\{1,1, \stackrel{m \text {-times }}{\cdots}, 1\}^{T}$ towards the required solution of the systems of equations for $m=10,20,50,100$. The corresponding so- 
lutions are: $x^{*}=(0.1004 \ldots, \cdots, 0.1004 \ldots)^{T},(0.0500 \ldots, \cdots, 0.0500 \ldots)^{T}$, $(0.0200 \ldots, \cdots, 0.0200 \ldots)^{T}$ and $(0.0100 \ldots, \cdots, 0.0100 \ldots)^{T}$.

Table 4. Comparison of performance of methods for Problem 1

\begin{tabular}{|c|c|c|c|c|c|c|c|c|}
\hline Methods & $M_{5,1}$ & $M_{6,1}$ & $M_{7,1}$ & $M_{8,1}$ & $M_{6,2}$ & $M_{6,3}$ & $M_{6,4}$ & $M_{6,5}$ \\
\hline \multicolumn{9}{|l|}{$m=10$} \\
\hline & 5 & 4 & 4 & 4 & 4 & 4 & 4 & 4 \\
\hline$\left\|x_{n+1}-x_{n}\right\|$ & $1.38(-791)$ & $3.95(-267)$ & $6.20(-424)$ & $6.27(-624)$ & $2.76(-251)$ & $4.92(-260)$ & $4.00(-243)$ & $1.67(-281)$ \\
\hline ACOC & 5.000 & 6.000 & 7.000 & 8.000 & 6.000 & 6.000 & 6.000 & 6.000 \\
\hline CPU-time & 2.7223 & 3.2304 & 2.8662 & 3.2815 & 3.0945 & 3.3622 & 2.8590 & 3.0793 \\
\hline \multicolumn{9}{|l|}{$m=20$} \\
\hline & -5 & 4 & 4 & 4 & 4 & 4 & 4 & 4 \\
\hline$\left\|x_{n+1}-x_{n}\right\|$ & $3.36(-964)$ & $1.31(-306)$ & $1.25(-518)$ & $2.49(-732)$ & $4.66(-281)$ & $1.22(-284)$ & $9.34(-273)$ & $1.40(-279)$ \\
\hline ACOC & 5.000 & 6.000 & 7.000 & 8.000 & 6.000 & 6.000 & 6.000 & 6.000 \\
\hline CPU-time & 6.2634 & 6.7892 & 6.3175 & 7.2813 & 7.1886 & 8.3434 & 6.9381 & 7.8244 \\
\hline \multicolumn{9}{|l|}{$m=50$} \\
\hline & - 4 & 4 & 4 & 4 & 4 & 4 & 4 & 4 \\
\hline$\left\|x_{n+1}-x_{n}\right\|$ & $3.35(-239)$ & $8.36(-369)$ & $7.97(-650)$ & $1.68(-894)$ & $4.54(-327)$ & $2.33(-328)$ & $1.19(-318)$ & $6.82(-301)$ \\
\hline $\mathrm{ACOC}$ & 5.000 & 6.000 & 7.000 & 8.000 & 6.000 & 6.000 & 6.000 & 6.000 \\
\hline CPU-time & 26.4392 & 28.0624 & 23.9223 & 25.9076 & 31.9847 & 38.5002 & 30.9372 & 38.7645 \\
\hline \multicolumn{9}{|l|}{$m=100$} \\
\hline & - 4 & 4 & 4 & 4 & 4 & 4 & 4 & 4 \\
\hline$\left\|x_{n+1}-x_{n}\right\|$ & $8.25(-276)$ & $1.49(-418)$ & $4.36(-751)$ & $1.84(-1022)$ & $4.43(-364)$ & $1.05(-364)$ & $1.28(-355)$ & $2.39(-323)$ \\
\hline $\mathrm{ACOC}$ & 5.000 & 6.000 & 7.000 & 8.000 & 6.000 & 6.000 & 6.000 & 6.000 \\
\hline CPU-time & 132.7194 & 128.3295 & 118.1720 & 124.1263 & 200.3748 & 274.5328 & 214.1123 & 285.5327 \\
\hline
\end{tabular}

Table 5. Comparison of performance of methods for Problem 2

\begin{tabular}{|c|c|c|c|c|c|c|c|c|}
\hline Methods & $M_{5,1}$ & $M_{6,1}$ & $M_{7,1}$ & $M_{8,1}$ & $M_{6,2}$ & $M_{6,3}$ & $M_{6,4}$ & $M_{6,5}$ \\
\hline \multicolumn{9}{|l|}{$m=10$} \\
\hline \multirow{6}{*}{$\begin{array}{r}\left\|x_{n+1}-x_{n}\right\| \\
\text { ACOC } \\
\text { CPU-time } \\
m=20 \\
\end{array}$} & 6 & 5 & 5 & 5 & 5 & 5 & 5 & \\
\hline & $9.45(-887)$ & $1.79(-353)$ & $2.94(-633)$ & $9.25(-1064)$ & $1.70(-546)$ & $1.45(-403)$ & $1.79(-488)$ & $8.67(-402)$ \\
\hline & 5.000 & 6.000 & 7.000 & 8.000 & 6.000 & 6.000 & 6.000 & 6.000 \\
\hline & 0.2572 & 0.2706 & 0.2655 & 0.2813 & 0.3754 & 0.4978 & 0.3754 & 0.4842 \\
\hline & & & & & & & & \\
\hline & $\begin{array}{ll}- & 6\end{array}$ & 5 & 5 & 5 & 5 & 5 & 5 & \\
\hline \multirow{3}{*}{$\begin{array}{r}\left\|x_{n+1}-x_{n}\right\| \\
\text { ACOC } \\
\text { CPU-time }\end{array}$} & $1.34(-887)$ & $2.53(-353)$ & $4.15(-633)$ & $1.31(-1063)$ & $2.40(-546)$ & $2.05(-403)$ & $2.53(-488)$ & $1.23(-401)$ \\
\hline & 5.000 & 6.000 & 7.000 & 8.000 & 6.000 & 6.000 & 6.000 & 6.000 \\
\hline & 0.3926 & 0.4389 & 0.4174 & 0.4536 & 0.6561 & 0.9680 & 0.6888 & 0.8286 \\
\hline \multicolumn{9}{|l|}{$m=50$} \\
\hline \multirow{4}{*}{$\begin{array}{r}n \\
\left\|x_{n+1}-x_{n}\right\| \\
\text { ACOC } \\
\text { CPU-time }\end{array}$} & 6 & 5 & 5 & 5 & 5 & 5 & 5 & \\
\hline & $2.13(-886)$ & $4.05(-353)$ & $6.63(-633)$ & $2.09(-1063)$ & $3.85(-546)$ & $3.27(-403)$ & $4.04(-488)$ & $1.96(-401)$ \\
\hline & 5.000 & 6.000 & 7.000 & 8.000 & 6.000 & 6.000 & 6.000 & 6.000 \\
\hline & 1.1252 & 1.1123 & 1.0345 & 1.1096 & 1.6243 & 2.4064 & 1.6872 & 2.1878 \\
\hline \multicolumn{9}{|l|}{$m=100$} \\
\hline \multirow{4}{*}{$\begin{array}{r}\| x_{n+1}{ }^{n} \\
\text { ACOC } \\
\text { CPU-time }\end{array}$} & 6 & 5 & 5 & 5 & 5 & 5 & 5 & \\
\hline & $2.99(-886)$ & $5.67(-353)$ & $9.28(-633)$ & $2.93(-1063)$ & $5.36(-546)$ & $4.57(-403)$ & $5.66(-488)$ & $2.74(-401)$ \\
\hline & 5.000 & 6.000 & 7.000 & 8.000 & 6.000 & 6.000 & 6.000 & 6.000 \\
\hline & 2.4853 & 2.3594 & 2.2284 & 2.3445 & 3.4696 & 5.4227 & 3.8134 & 4.9695 \\
\hline
\end{tabular}

Problem 2. Next, considering the system [13]:

$$
\left\{\begin{array}{l}
x_{i}^{2} x_{i+1}-1,1 \leq i \leq m-1, \\
x_{i}^{2} x_{1}-1, i=m
\end{array}\right.
$$

with initial value $x_{0}=\left\{\frac{3}{2}, \frac{3}{2},{ }^{m-\text { times }}, \frac{3}{2}\right\}^{T}$ towards the required solution of the systems of equations for $m=10,20,50,100$. The corresponding solutions are: $x^{*}=(1,1, \cdots, 1)^{T},(1,1, \cdots, 1)^{T},(1,1, \cdots, 1)^{T}$ and $(1,1, \cdots, 1)^{T}$. 
Table 6. Comparison of performance of methods for Problem 3

\begin{tabular}{|c|c|c|c|c|c|c|c|c|}
\hline Methods & $M_{5,1}$ & $M_{6,1}$ & $M_{7,1}$ & $M_{8,1}$ & $M_{6,2}$ & $M_{6,3}$ & $M_{6,4}$ & $M_{6,5}$ \\
\hline \multicolumn{9}{|l|}{$m=10$} \\
\hline & 5 & 5 & 5 & 4 & 5 & 5 & 5 & 5 \\
\hline \multirow{5}{*}{$\begin{array}{r}\left\|x_{n+1}-x_{n}\right\| \\
\text { ACOC } \\
\text { CPU-time } \\
m=20 \\
m\end{array}$} & $7.08(-359)$ & $6.02(-641)$ & $3.84(-1298)$ & $2.50(-246)$ & $1.01(-835)$ & $3.87(-688)$ & $2.54(-534)$ & $2.64(-984)$ \\
\hline & 5.000 & 6.000 & 7.000 & 8.000 & 6.000 & 6.000 & 6.000 & 6.000 \\
\hline & 0.2355 & 0.2501 & 0.2445 & 0.2872 & 0.3288 & 0.4067 & 0.3284 & 0.3749 \\
\hline & & & & & & & & \\
\hline & 5 & 5 & 5 & 4 & 5 & 5 & 5 & 5 \\
\hline \multirow{4}{*}{$\begin{array}{r}\left\|x_{n+1}-x_{n}\right\| \\
\text { ACOC } \\
\text { CPU-time } \\
m=50\end{array}$} & $3.53(-360)$ & $9.40(-644)$ & $5.61(-1304)$ & $1.87(-247)$ & $6.21(-837)$ & $3.50(-690)$ & $9.33(-536)$ & $2.60(-988)$ \\
\hline & 5.000 & 6.000 & 7.000 & 8.000 & 6.000 & 6.000 & 6.000 & 6.000 \\
\hline & 0.3764 & 0.4375 & 0.3607 & 0.3758 & 0.5313 & 0.7192 & 0.5637 & 0.7028 \\
\hline & & & & & & & & \\
\hline \multirow{5}{*}{$\begin{array}{r}n \\
\left\|x_{n+1}-x_{n}\right\| \\
\text { ACOC } \\
\text { CPU-time } \\
m=100 \\
\end{array}$} & 5 & 5 & 5 & 4 & 5 & 5 & 5 & 5 \\
\hline & $1.95(-360)$ & $1.76(-644)$ & $1.19(-1305)$ & $1.17(-247)$ & $3.64(-837)$ & $1.13(-690)$ & $4.63(-536)$ & $1.96(-989)$ \\
\hline & 5.000 & 6.000 & 7.000 & 8.000 & 6.000 & 6.000 & 6.000 & 6.000 \\
\hline & 0.9692 & 1.0475 & 0.9893 & 1.0697 & 1.3755 & 1.9221 & 1.5315 & 1.9534 \\
\hline & & & & & & & & \\
\hline \multirow{4}{*}{$\begin{array}{r}n \\
\left\|x_{n+1}-x_{n}\right\| \\
\text { ACOC } \\
\text { CPU-time }\end{array}$} & 5 & 5 & 5 & 4 & 5 & 5 & 5 & 5 \\
\hline & $2.35(-360)$ & $1.79(-644)$ & $8.72(-1306)$ & $1.44(-247)$ & $4.41(-837)$ & $1.25(-690)$ & $5.48(-536)$ & $1.74(-989)$ \\
\hline & 5.000 & 6.000 & 7.000 & 8.000 & 6.000 & 6.000 & 6.000 & 6.000 \\
\hline & 2.1852 & 2.1340 & 1.9538 & 1.9894 & 3.4066 & 4.1125 & 2.9854 & 4.4078 \\
\hline
\end{tabular}

Problem 3. The boundary value problem, $u^{\prime \prime}+u^{3}=0, u(0)=0, u(1)=1$, is studied (see [12]). Consider the following partitioning of the interval $[0,1]$ :

$$
t_{0}=0<t_{1}<t_{2}<\cdots<t_{l-1}<t_{l}=1, \quad t_{j+1}=t_{j}+h, \quad h=1 / l .
$$

Let us define $u_{0}=u\left(t_{0}\right)=0, u_{1}=u\left(t_{1}\right), \ldots, u_{l-1}=u\left(t_{l-1}\right), u_{l}=u\left(t_{l}\right)=1$. If we discretize the problem by using the numerical formula of central differences then we obtain a system of $l-1$ nonlinear equations in $l-1$ variables

$$
u_{m-1}-2 u_{m}+u_{m+1}+h^{2} u_{m}^{3}=0, \quad(m=1,2,3, \ldots, l-1) .
$$

In particular, we solve this problem for $l=11,21,51,101$ so that $m=10$, $20,50,100$ by selecting $u^{(0)}=\{1,1, \stackrel{m \text {-times }}{\cdots}, 1\}^{T}$ as the initial value. Their corresponding solutions are given by

$$
\begin{aligned}
\{0.0959 \ldots, 0.1919 \ldots, 0.2878 \ldots, 0.3835 \ldots, 0.4787 \ldots, 0.5730 \ldots, 0.6658 \ldots, \\
0.7561 \ldots, 0.8429 \ldots, 0.9247 \ldots\}^{T}, \\
\{0.0502 \ldots, 0.1005 \ldots, 0.1508 \ldots, 0.2011 \ldots, 0.2514 \ldots, 0.3016 \ldots, 0.3518 \ldots, \\
0.4018 \ldots, 0.4517 \ldots, 0.5014 \ldots, 0.5509 \ldots, 0.5999 \ldots, 0.6485 \ldots, 0.6964 \ldots, \\
0.7436 \ldots, 0.7898 \ldots, 0.8349 \ldots, 0.8787 \ldots, 0.9210 \ldots, 0.9615 \ldots\}^{T}, \\
\{0.0207 \ldots, 0.0414 \ldots, 0.0621 \ldots, 0.0828 \ldots, 0.1035 \ldots, 0.1242 \ldots, 0.1449 \ldots, \\
0.1656 \ldots, 0.1863 \ldots, 0.2070 \ldots, 0.2277 \ldots, 0.2484 \ldots, 0.2691 \ldots, 0.2898 \ldots, \\
0.3105 \ldots, 0.3312 \ldots, 0.3518 \ldots, 0.3724 \ldots, 0.3930 \ldots, 0.4136 \ldots, 0.4342 \ldots, \\
0.4547 \ldots, 0.4752 \ldots, 0.4957 \ldots, 0.5161 \ldots, 0.5364 \ldots, 0.5567 \ldots, 0.5769 \ldots,
\end{aligned}
$$




$$
\begin{aligned}
& 0.5971 \ldots, 0.6172 \ldots, 0.6372 \ldots, 0.6570 \ldots, 0.6768 \ldots, 0.6965 \ldots, 0.7160 \ldots, \\
& 0.7354 \ldots, 0.7546 \ldots, 0.7737 \ldots, 0.7925 \ldots, 0.8112 \ldots, 0.8297 \ldots, 0.8480 \ldots, \\
& 0.8660 \ldots, 0.8838 \ldots, 0.9013 \ldots, 0.9186 \ldots, 0.9355 \ldots, 0.9521 \ldots, 0.9684 \ldots, \\
& 0.9844 \ldots\}^{T}, \\
& \{0.0104 \ldots, 0.0209 \ldots, 0.0313 \ldots, 0.0418 \ldots, 0.0522 \ldots, 0.0627 \ldots, 0.0732 \ldots, \\
& 0.0836 \ldots, 0.0941 \ldots, 0.1045 \ldots, 0.1150 \ldots, 0.1255 \ldots, 0.1359 \ldots, 0.1464 \ldots, \\
& 0.1568 \ldots, 0.1673 \ldots, 0.1777 \ldots, 0.1882 \ldots, 0.1986 \ldots, 0.2091 \ldots, 0.2196 \ldots, \\
& 0.2300 \ldots, 0.2405 \ldots, 0.2509 \ldots, 0.2614 \ldots, 0.2718 \ldots, 0.2822 \ldots, 0.2927 \ldots, \\
& 0.3031 \ldots, 0.3136 \ldots, 0.3240 \ldots, 0.3344 \ldots, 0.3449 \ldots, 0.3553 \ldots, 0.3657 \ldots, \\
& 0.3761 \ldots, 0.3865 \ldots, 0.3969 \ldots, 0.4073 \ldots, 0.4177 \ldots, 0.4281 \ldots, 0.4385 \ldots, \\
& 0.4488 \ldots, 0.4592 \ldots, 0.4695 \ldots, 0.4799 \ldots, 0.4902 \ldots, 0.5005 \ldots, 0.5108 \ldots, \\
& 0.5211 \ldots, 0.5314 \ldots, 0.5417 \ldots, 0.5519 \ldots, 0.5621 \ldots, 0.5724 \ldots, 0.5826 \ldots, \\
& 0.5927 \ldots, 0.6029 \ldots, 0.6130 \ldots, 0.6231 \ldots, 0.6332 \ldots, 0.6433 \ldots, 0.6533 \ldots, \\
& 0.6633 \ldots, 0.6733 \ldots, 0.6832 \ldots, 0.6932 \ldots, 0.7031 \ldots, 0.7129 \ldots, 0.7227 \ldots, \\
& 0.7325 \ldots, 0.7422 \ldots, 0.7519 \ldots, 0.7616 \ldots, 0.7712 \ldots, 0.7808 \ldots, 0.7903 \ldots, \\
& 0.7998 \ldots, 0.8092 \ldots, 0.8186 \ldots, 0.8279 \ldots, 0.8372 \ldots, 0.8464 \ldots, 0.8555 \ldots, \\
& 0.8646 \ldots, 0.8736 \ldots, 0.8826 \ldots, 0.8915 \ldots, 0.9003 \ldots, 0.9091 \ldots, 0.9177 \ldots, \\
& 0.9263 \ldots, 0.9348 \ldots, 0.9433 \ldots, 0.9516 \ldots, 0.9599 \ldots, 0.9681 \ldots, 0.9762 \ldots, \\
& 0.9842 \ldots, 0.9921 \ldots\}^{T}
\end{aligned}
$$

Numerical results are displayed in Tables 4-6, which include: (i) dimension $(m)$ of the system of equations, (ii) required number of iterations $(n)$, (iii) error $\left\|x_{n+1}-x_{n}\right\|$ of approximation to the corresponding solution of considered problems, wherein $a(-h)$ denotes $a \times 10^{-h}$, (iv) approximate computational order of convergence (ACOC) and (v) elapsed CPU time (CPU-time) in seconds.

From the numerical results shown in Tables $4-6$ it is clear that the methods show stable convergence behavior. From the calculation of computational order of convergence, it is also verified that order of convergence is preserved. Elapsed CPU time shows the efficient nature of presented methods as compare to existing ones. Moreover, the efficiency results shown in Theorem 4 are in complete agreement with CPU-time utilized in the execution of program. Similar numerical experimentations, carried out for a number of problems of different type, have confirmed the above conclusions to a large extent.

\section{References}

[1] I.K. Argyros. Convergence and Applications of Newton-type Iterations. SpringerVerlag, New York, 2008.

[2] I.K. Argyros and Á.A. Magreñán. Ball convergence theorems and the convergence planes of an iterative methods for nonlinear equations. SeMa, 71(1):39-55, 2015. https://doi.org/10.1007/s40324-015-0047-8.

[3] D.K.R. Babajee, M.Z. Dauhoo, M.T. Darvishi, A. Karami and A. Barati. Analysis of two Chebyshev-like third order methods free from second derivatives for solving systems of nonlinear equations. J. Comput. Appl. Math., 233(8):20022012, 2010. https://doi.org/10.1016/j.cam.2009.09.035. 
[4] R. Behl, A. Cordero, S.S. Motsa and J.R. Torregrosa. Stable high-order iterative methods for solving nonlinear models. Appl. Math. Comput., 303(15):70-88, 2017. https://doi.org/10.1016/j.amc.2017.01.029.

[5] A. Cordero, J.L. Hueso, E. Martínez and J.R. Torregrosa. A modified Newton-Jarratt's composition. Numer. Algor., 55(1):87-99, 2010. https://doi.org/10.1007/s11075-009-9359-z.

[6] A. Cordero and J.R. Torregrosa. Variants of Newton's method using fifthorder quadrature formulas. Appl. Math. Comput., 190(1):686-698, 2007. https://doi.org/10.1016/j.amc.2007.01.062.

[7] M.T Darvishi and A. Barati. Super cubic iterative methods to solve systems of nonlinear equations. Appl. Math. Comput., 188(2):1678-1685, 2007. https://doi.org/10.1016/j.amc.2006.11.022.

[8] H. Esmaeili and M. Ahmadi. An efficient three-step method to solve system of non linear equations. Appl. Math. Comput., 266:1093-1101, 2015. https://doi.org/10.1016/j.amc.2015.05.076.

[9] M. Grau and J.L. Díaz-Barrero. An improvement of the EulerChebyshev iterative method. J. Math. Anal. Appl., 315:1-7, 2006. https://doi.org/10.1016/j.jmaa.2005.09.086.

[10] M. Grau-Sánchez, À. Grau and M. Noguera. Ostrowski type methods for solving systems of nonlinear equations. Appl. Math. Comput., 218(6):2377-2385, 2011. https://doi.org/10.1016/j.amc.2011.08.011.

[11] T. Lotfi, P. Bakhtiari, A. Cordero, K. Mahdiani and J.R. Torregrosa. Some new efficient multipoint iterative methods for solving nonlinear systems of equations. Int. J. Comput. Math., 92(9):1921-1934, 2015. https://doi.org/10.1080/00207160.2014.946412.

[12] J.M. Ortega and W.C. Rheinboldt. Iterative Solution of Nonlinear Equations in Several Variables. Academic Press, New York, 1970.

[13] J.R. Sharma and H. Arora. A novel derivative free algorithm with seventh order convergence for solving systems of nonlinear equations. Numer. Algor., 67(4):917-933, 2014. https://doi.org/10.1007/s11075-014-9832-1.

[14] J.R. Sharma, R. Sharma and A. Bahl. An improved Newton-Traub composition for solving systems of nonlinear equations. Appl. Math. Comput., 290:98-110, 2016. https://doi.org/10.1016/j.amc.2016.05.051.

[15] S. Weerakoon and T.G.I. Fernando. A variant of Newton's method with accelerated third order convergence. Appl. Math. Lett., 13(8):87-93, 2000. https://doi.org/10.1016/S0893-9659(00)00100-2.

[16] S. Wolfram. The Mathematica Book. 5th edn, Wolfram Media, 2003. 